\title{
Three years of greenhouse gas column-averaged dry air mole fractions retrieved from satellite - Part 1: Carbon dioxide
}

\author{
O. Schneising, M. Buchwitz, J. P. Burrows, H. Bovensmann, M. Reuter, J. Notholt, R. Macatangay, and T. Warneke \\ Institute of Environmental Physics (IUP), University of Bremen FB1, Bremen, Germany
}

Received: 25 January 2008 - Published in Atmos. Chem. Phys. Discuss.: 18 March 2008

Revised: 13 June 2008 - Accepted: 27 June 2008 - Published: 21 July 2008

\begin{abstract}
Carbon dioxide $\left(\mathrm{CO}_{2}\right)$ and methane $\left(\mathrm{CH}_{4}\right)$ are the two most important anthropogenic greenhouse gases. SCIAMACHY on ENVISAT is the first satellite instrument whose measurements are sensitive to concentration changes of the two gases at all altitude levels down to the Earth's surface where the source/sink signals are largest. We have processed three years (2003-2005) of SCIAMACHY nearinfrared nadir measurements to simultaneously retrieve vertical columns of $\mathrm{CO}_{2}$ (from the $1.58 \mu \mathrm{m}$ absorption band), $\mathrm{CH}_{4}(1.66 \mu \mathrm{m})$ and oxygen $\left(\mathrm{O}_{2}\right.$ A-band at $\left.0.76 \mu \mathrm{m}\right)$ using the scientific retrieval algorithm WFM-DOAS. We show that the latest version of WFM-DOAS, version 1.0, which is used for this study, has been significantly improved with respect to its accuracy compared to the previous versions while essentially maintaining its high processing speed $(\sim 1$ min per orbit, corresponding to $\sim 6000$ single measurements, and per gas on a standard PC). The greenhouse gas columns are converted to dry air column-averaged mole fractions, denoted $\mathrm{XCO}_{2}$ (in ppm) and $\mathrm{XCH}_{4}$ (in ppb), by dividing the greenhouse gas columns by simultaneously retrieved dry air columns. For $\mathrm{XCO}_{2}$ dry air columns are obtained from the retrieved $\mathrm{O}_{2}$ columns. For $\mathrm{XCH}_{4}$ dry air columns are obtained from the retrieved $\mathrm{CO}_{2}$ columns because of better cancellation of light path related errors compared to using $\mathrm{O}_{2}$ columns retrieved from the spectrally distant $\mathrm{O}_{2}$ Aband. Here we focus on a discussion of the $\mathrm{XCO}_{2}$ data set. The $\mathrm{XCH}_{4}$ data set is discussed in a separate paper (Part 2). In order to assess the quality of the retrieved $\mathrm{XCO}_{2}$ we present comparisons with Fourier Transform Spectroscopy (FTS) $\mathrm{XCO}_{2}$ measurements at two northern hemispheric mid-latitude ground stations. To assess the quality globally, we present detailed comparisons with global $\mathrm{XCO}_{2}$ fields obtained from NOAA's $\mathrm{CO}_{2}$ assimilation system Car-
\end{abstract}

bonTracker. For the Northern Hemisphere we find good agreement with the reference data for the $\mathrm{CO}_{2}$ seasonal cycle and the $\mathrm{CO}_{2}$ annual increase. For the Southern Hemisphere, where significantly less data are available for averaging compared to the Northern Hemisphere, the $\mathrm{CO}_{2}$ annual increase is also in good agreement with CarbonTracker but the amplitude and phase of the seasonal cycle show systematic differences (up to several ppm) arising partially from the $\mathrm{O}_{2}$ normalization most likely caused by unconsidered scattering effects due to subvisual cirrus clouds. The retrieved $\mathrm{XCO}_{2}$ regional pattern at monthly resolution over various regions show clear correlations with CarbonTracker but also significant differences. Typically the retrieved variability is about $4 \mathrm{ppm}$ ( $1 \%$ of $380 \mathrm{ppm}$ ) higher but depending on time and location differences can reach or even exceed $8 \mathrm{ppm}$. Based on the error analysis and on the comparison with the reference data we conclude that the $\mathrm{XCO}_{2}$ data set can be characterized by a single measurement retrieval precision (random error) of $1-2 \%$, a systematic low bias of about $1.5 \%$, and by a relative accuracy of about $1-2 \%$ for monthly averages at a spatial resolution of about $7^{\circ} \times 7^{\circ}$. When averaging the SCIAMACHY $\mathrm{XCO}_{2}$ over all three years we find elevated $\mathrm{CO}_{2}$ over the highly populated region of western central Germany and parts of the Netherlands ("Rhine-Main area") reasonably well correlated with EDGAR anthropogenic $\mathrm{CO}_{2}$ emissions. On average the regional enhancement is $2.7 \mathrm{ppm}$ including an estimated contribution of $1-1.5 \mathrm{ppm}$ due to aerosol related errors and sampling.

\section{Correspondence to: $\mathrm{M}$. Buchwitz (michael.buchwitz@iup.physik.uni- bremen.de)}

Published by Copernicus Publications on behalf of the European Geosciences Union. 


\section{Introduction}

The atmospheric greenhouse gas carbon dioxide $\left(\mathrm{CO}_{2}\right)$ has increased significantly since pre-industrial times primarily as a result of fossil fuel combustion, land use change, cement production, and biomass burning, thus perturbing the natural global carbon cycle. Increasing $\mathrm{CO}_{2}$ is predicted to result in a warmer climate with adverse consequences, such as rising sea levels and an increase of extreme weather conditions (IPCC, 2001, 2007). The reliable prediction of future atmospheric $\mathrm{CO}_{2}$ levels and the associated global climate change requires an adequate understanding of the $\mathrm{CO}_{2}$ sources and sinks. Unfortunately, this understanding has significant gaps and uncertainties are large (see, e.g., Stephens et al., 2007).

The current knowledge of the carbon dioxide surface fluxes is limited for example by the sparseness of the groundbased network with a lack of high-frequency surface observations in continental regions particularly outside North America and Europe. Theoretical studies have shown that satellite measurements of $\mathrm{CO}_{2}$ in combination with models have the potential to significantly reduce $\mathrm{CO}_{2}$ surface flux uncertainties (Rayner and O'Brien, 2001; Houweling et al., 2004). Existing satellite instruments whose measurements are sensitive to atmospheric $\mathrm{CO}_{2}$ either measure radiances in the thermal infrared (TIR) spectral region such as HIRS (Chédin et al., 2002, 2003) and AIRS (Engelen et al., 2004; Engelen and McNally, 2005; Aumann et al., 2005; Strow et al., 2006) or SCIAMACHY in the near-infrared (NIR)/short wave infrared (SWIR) spectral region (Buchwitz et al., 2005a,b, 2006a, 2007b; Houweling et al., 2005; Bösch et al., 2006; Barkley et al., 2006a,b,c, 2007). Note that in this paper NIR and SWIR are commonly referred to as NIR. Whereas the TIR nadir measurements are primarily sensitive to middle to upper tropospheric $\mathrm{CO}_{2}$, the NIR nadir measurements are sensitive to all altitude levels, including the boundary layer, which permits the retrieval of $\mathrm{CO}_{2}$ total columns. High sensitivity to $\mathrm{CO}_{2}$ concentration variations near the Earth's surface is important in order to get information on regional $\mathrm{CO}_{2}$ sources and sinks. SCIAMACHY is the first and currently only satellite instrument which measures reflected solar radiation in the NIR spectral region covering important absorption bands of $\mathrm{CO}_{2}$ (as well as $\mathrm{CH}_{4}$ and $\mathrm{O}_{2}$ ). For the near future other satellite missions are planned, most notably OCO (Crisp et al., 2004) and GOSAT (Hamazaki et al., 2004), which will also perform nadir observations in the NIR spectral region to retrieve $\mathrm{CO}_{2}$.

As topographic features and surface pressure changes impact on the $\mathrm{CO}_{2}$ total column, a more useful quantity for inverse modeling is the column-averaged dry air mole fraction of $\mathrm{CO}_{2}$, denoted $\mathrm{XCO}_{2}$, being defined as the total column of carbon dioxide divided by the dry air column. Dry air columns can be estimated by the simultaneous measurement of molecular oxygen $\left(\mathrm{O}_{2}\right)$ which is a well mixed gas with accurately known mole fraction exhibiting negligible (relative) variability. As $\mathrm{CO}_{2}$ is a long-lived gas, the amount of the increase or decrease of its column-averaged mole fraction, as a result of a source or sink, is determined primarily by the strength and the spatial size of the source or sink and atmospheric transport. Although point sources such as the plumes from chimneys have large mole fractions locally, at the grid sizes of typical models or at the spatial resolution of the SCIAMACHY nadir measurements, sources and sinks only result in small changes of the column-averaged mole fractions on top of a large background. In order to determine such changes well, the resultant requirements on the accuracy and precision of the measurements of the columnaveraged dry air mole fractions from space are demanding, being of the order of $1 \%$ or better (Rayner and O'Brien, 2001; Houweling et al., 2004; Miller et al., 2007; Chevallier et al., 2007).

Inverse modeling to obtain surface fluxes of carbon dioxide globally using the highly precise and accurate surface observations mostly based on weekly sampling relies on various assumptions (e.g., assumed flux pattern and uncertainties) and is currently typically restricted to large spatial scales (continents, ocean basins) due to the sparseness of the surface network (Bousquet et al., 1999; Gurney et al., 2002; Rödenbeck et al., 2003; Patra et al., 2006). In addition, attempts have been made for selected regions to better constrain the regional fluxes using continuous high-frequency $\mathrm{CO}_{2}$ in-situ observations (Derwent et al., 2002; Peylin et al., 2005). As pointed out by Peylin et al. (2005), these regional results also depend critically on several assumptions used such as required smoothness, initial conditions, and the global flux field. As described above, inverse modeling of the $\mathrm{CO}_{2}$ sources and sinks using satellite derived $\mathrm{CO}_{2}$ columns has the potential to improve this situation but until now has not been undertaken due to lack of satellite data with sufficient quality.

In this manuscript, the first multi-year global dry air column-averaged $\mathrm{CO}_{2}$ data set from SCIAMACHY is presented and discussed. A short first discussion of this data set has already been given in Buchwitz et al. (2007b) focussing on northern hemispheric large scale $\mathrm{CO}_{2}$ features such as the seasonal cycle and the annual increase. The retrieval technique, called Weighting Function Modified DOAS, WFMDOAS, developed at the University of Bremen for the retrieval of trace gases from SCIAMACHY has been described elsewhere (Buchwitz et al., 2000b; Buchwitz and Burrows, 2004; Buchwitz et al., 2005a,b). Other groups have developed somewhat different approaches to retrieve $\mathrm{XCO}_{2}$ or $\mathrm{CO}_{2}$ columns from SCIAMACHY. For example the column-averaged mole fractions retrieved using the computationally much more expensive Full Spectral Initiation WFM-DOAS (FSI/WFM-DOAS) algorithm (Barkley et al., 2006a,b,c, 2007) are obtained by normalizing the retrieved $\mathrm{CO}_{2}$ column with surface pressure from meteorological analysis and not, as done here, by normalizing with simultaneously measured $\mathrm{O}_{2}$. Houweling et al. (2005), using another algorithm for the retrieval of $\mathrm{CO}_{2}$ column amounts 

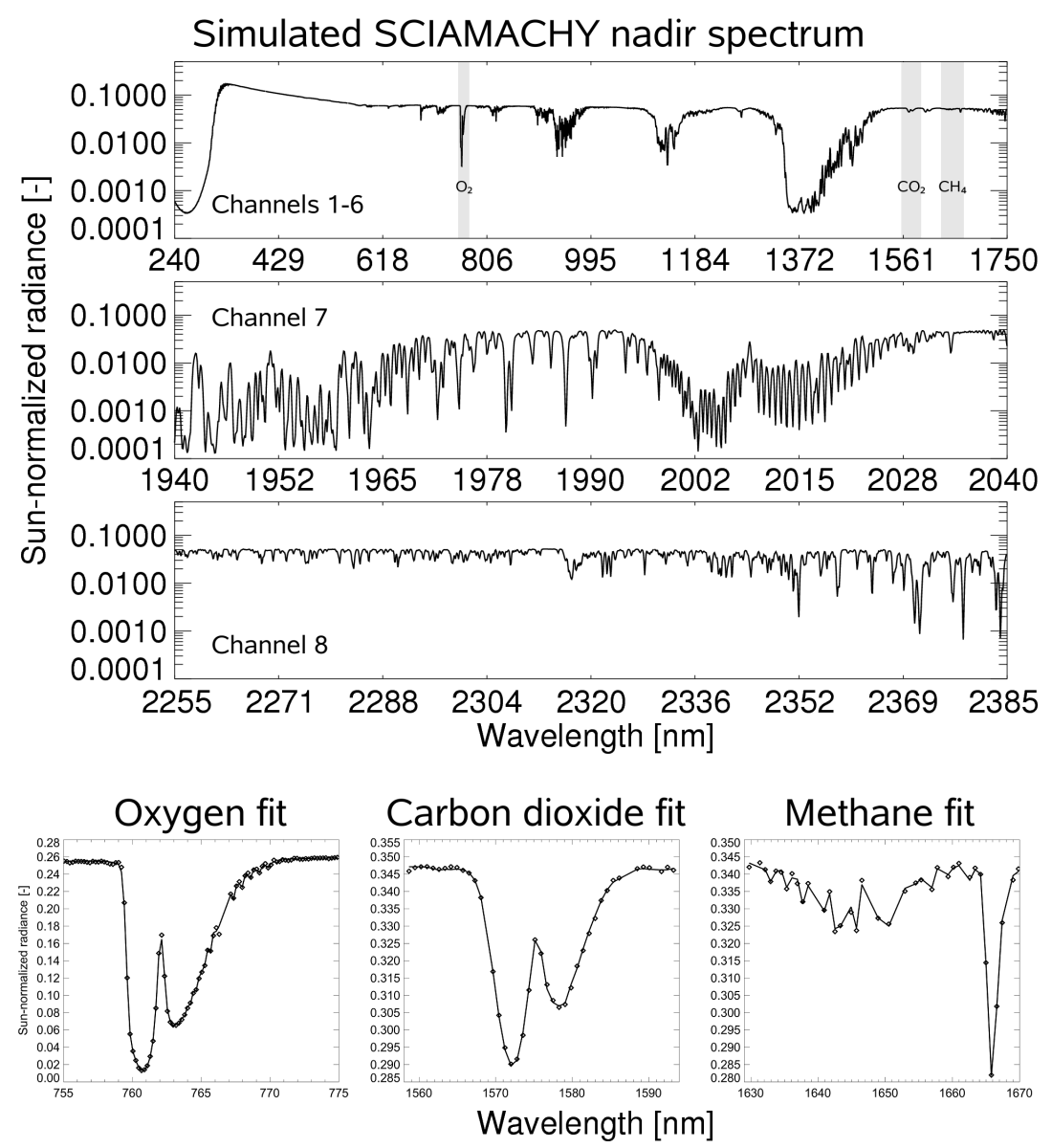

Fig. 1. SCIAMACHY nadir spectrum, simulated with the radiative transfer model SCIATRAN (Buchwitz et al., 2000a,b), covering the entire spectral region observed by SCIAMACHY (top). The three spectral fitting windows for $\mathrm{O}_{2}, \mathrm{CO}_{2}$, and $\mathrm{CH}_{4}$ as used by WFM-DOAS version 1.0 are indicated by the shaded areas. WFM-DOAS example fits are shown below (the symbols are the SCIAMACHY measurements, the solid lines correspond to the fitted WFM-DOAS linearized radiative transfer model). A detailed discussion of the methane results is given in Schneising et al. (2008) (Part 2). Shown in the top panel are also channel 7 and channel 8 which cover many $\mathrm{CO}_{2}$ and $\mathrm{CH}_{4}$ absorption lines but are not used for WFM-DOAS version 1.0 due to systematic retrieval errors caused by the varying ice layers on the cold detectors.

from SCIAMACHY data, have identified problems due to aerosols especially when there are strong desert dust storms. Here we show that normalizing with measured $\mathrm{O}_{2}$ reduces dust storm aerosol related errors. On the other hand we also show that normalizing with measured $\mathrm{O}_{2}$ can be problematic under specific conditions because of the different sensitivity of the radiances in the spectral regions used for $\mathrm{CO}_{2}$ and $\mathrm{O}_{2}$ column retrieval.

This manuscript is organized as follows: In Sect. 2 the SCIAMACHY instrument and its measurement principle are introduced and explained. This is followed by a description of the WFM-DOAS retrieval algorithm in Sect. 3 and an error analysis in Sect. 4. The new SCIAMACHY multi-year carbon dioxide data set is discussed in Sect. 5. Conclusions are given in Sect. 6.

\section{The SCIAMACHY instrument}

SCIAMACHY, which is a multi-national (Germany, The Netherlands, Belgium) contribution to the European environmental satellite ENVISAT, is a grating spectrometer that measures reflected, backscattered and transmitted solar radiation upwelling from the top of the atmosphere (Burrows et al., 1990; Burrows and Chance, 1991; Burrows et al., 1995; Bovensmann et al., 1999). The spectral region from $214 \mathrm{~nm}$ to $1750 \mathrm{~nm}$ is measured contiguously in six channels, and there are two additional channels covering the regions 19402040 and 2265-2380 nm (see Fig. 1). Each spectral channel comprises a grating focusing optics and a 1024 element monolithic diode array. In addition, SCIAMACHY has 7 broad band channels, the Polarization Monitoring Devices (PMD), which monitor the upwelling radiation polarized with respect to the instrument plane at high spatial resolution 
providing sub-pixel information used in this study to identify cloud contaminated ground pixels.

ENVISAT was launched into a sun synchronous orbit in descending node having an equator crossing time of 10:00 a.m. local time. During every orbit calibration measurements are made during the eclipse, followed by a solar occultation and limb atmospheric measurement. On the Earth's day side SCIAMACHY performs alternate nadir and limb observations. These measurements can be inverted to obtain a large number of atmospheric data products (Bovensmann et al., 1999). Of relevance to this study are the column amounts of $\mathrm{CO}_{2}$ and $\mathrm{O}_{2}$. As a result of SCIAMACHY's observation of greenhouse gas overtone absorptions in the nearinfrared/short wave infrared (NIR/SWIR) solar backscattered spectrum, SCIAMACHY is the first satellite instrument that yields the vertical columns of $\mathrm{CO}_{2}$ with high sensitivity down to the Earth's surface (Buchwitz et al., 2005a). As the integration time for the detectors is optimized around an orbit, the horizontal resolution of the nadir measurements depends on orbital position and spectral interval, but is typically $60 \mathrm{~km}$ across track by $30 \mathrm{~km}$ along track for the spectral fitting windows used in this study.

Overall, the in-flight optical performance of SCIAMACHY is very similar to that predicted from the pre-flight on ground characterization and calibration activities. One exception is a time dependent optical throughput variation in the SCIAMACHY NIR/SWIR channel 7, which has many resolved $\mathrm{CO}_{2}$ absorption features, and channel 8, which has many $\mathrm{CH}_{4}$ absorption features. This results from the in-flight deposition of ice on the detectors. As ice absorbs and scatters at these wavelengths this adversely affects the trace gas retrieval by reducing the signal to noise and changing the instrument slit function (Gloudemans et al., 2005; Buchwitz et al., 2005b). As shown in Fig. 1, the WFM-DOAS version 1.0 results presented in this manuscript have been derived using $\mathrm{CO}_{2}$ absorption features in channel $6(1000-1750 \mathrm{~nm})$ and $\mathrm{O}_{2}$ A-band absorption in channel $4(605-805 \mathrm{~nm})$, which are not affected by an ice-layer, as their detectors operate at higher temperatures.

\section{WFM-DOAS retrieval algorithm}

The retrieval of a long-lived and therefore relatively wellmixed gas such as carbon dioxide is challenging as only the small variations on top of a large background yield information on their surface sources and sinks. The retrieval algorithm has therefore to be accurate and, in addition, sufficiently fast to process the large amounts of data produced by SCIAMACHY. At the University of Bremen the Weighting Function Modified Differential Optical Absorption Spectroscopy (WFM-DOAS) retrieval technique (Buchwitz et al., $2000 \mathrm{~b}$ ) has been developed for the retrieval of trace gases and optimized for the retrieval of $\mathrm{CO}_{2}, \mathrm{CH}_{4}$ and $\mathrm{O}_{2}$. The results for methane are discussed in Schneising et al. (2008) (Part 2).
The algorithm has been described in detail elsewhere (Buchwitz et al., 2000b; Buchwitz and Burrows, 2004; Buchwitz et al., 2005a,b). We therefore focus on a discussion of the main differences between the current version 1.0, which has been used to generate the data set discussed in this manuscript, and the previous version 0.4 (Buchwitz et al., 2005a,b; Dils et al., 2006a; Warneke et al., 2005).

\subsection{Retrieval of vertical columns}

WFM-DOAS is a least-squares method based on scaling (or shifting) pre-selected atmospheric vertical profiles. The fit parameters for the trace gases yield directly the desired vertical columns. The logarithm of a linearized radiative transfer model plus a low-order polynomial $P_{i}(\hat{\mathbf{a}})$ is fitted to the logarithm of the ratio of the measured nadir radiance and solar irradiance spectrum, i.e., the observed sun-normalized radiance $I^{\text {obs }}$. The least-squares WFM-DOAS equation can be written as follows (the fit parameter vectors or vector components are indicated by a hat):

$$
\sum_{i=1}^{m}\left(\ln I_{i}^{\text {obs }}-\ln I_{i}^{\bmod }(\hat{\mathbf{V}}, \hat{\mathbf{a}})\right)^{2} \equiv\|\mathbf{R E S}\|^{2} \rightarrow \min .
$$

where the linearized radiative transfer model is given by

$$
\begin{aligned}
\ln I_{i}^{\bmod }(\hat{\mathbf{V}}, \hat{\mathbf{a}}) & =\ln I_{i}^{\bmod }(\overline{\mathbf{V}}) \\
& +\left.\sum_{j=1}^{J} \frac{\partial \ln I_{i}^{\bmod }}{\partial V_{j}}\right|_{\bar{V}_{j}} \times\left(\hat{V}_{j}-\bar{V}_{j}\right)+P_{i}(\hat{\mathbf{a}}) .
\end{aligned}
$$

Index $i$ refers to the center wavelength $\lambda_{i}$ of detector pixel number $i$. The components of vector $\boldsymbol{V}$, denoted $V_{j}$, are the vertical columns of all trace gases which have absorption lines in the selected spectral fitting window (interfering gas for the $\mathrm{CO}_{2}$ fit is $\mathrm{H}_{2} \mathrm{O}$; for the $\mathrm{CH}_{4}$ fit interfering gases are $\mathrm{H}_{2} \mathrm{O}$ and $\mathrm{CO}_{2}$ ). The fit parameters are the desired trace gas vertical columns $\hat{V}_{j}$ and the polynomial coefficients which are the components of vector $\hat{\mathbf{a}}$. An additional fit parameter also used (but for simplicity omitted in the equations given here) is the shift (in Kelvin) of a pre-selected temperature profile. This fit parameter has been added in order to take the temperature dependence of the trace gas absorption cross-sections into account. The fit parameter values are determined by minimising (in a linear least-squares sense) the difference between observation ( $\ln I_{i}^{\mathrm{obs}}$ ) and WFM-DOAS model ( $\ln I_{i}^{\text {mod }}$ ), i.e. the "length" of fit residuum vector RES (with components $\mathbf{R E S}_{i}$ ) for all spectral points $\lambda_{i}$ simultaneously. A derivative with respect to a vertical column refers to the change of the top-of-atmosphere radiance caused by a change (here: scaling) of a pre-selected trace gas vertical profile. The WFM-DOAS reference spectra are the logarithm of the sun-normalized radiance and its derivatives. They are computed with a radiative transfer model (Buchwitz et al., 2000a) for assumed (e.g. climatological) "mean" columns $\overline{\mathbf{V}}$. Multiple scattering is fully taken into account. 
The least-squares problem can also be expressed in the following vector/matrix notation: Minimize $\|\mathbf{y}-\mathbf{A} \mathbf{x}\|^{2}$ with respect to $\mathbf{x}$. The solution is $\hat{\mathbf{x}}=\mathbf{C}_{\mathbf{x}} \mathbf{A}^{T} \mathbf{y}$ where $\mathbf{C}_{\mathbf{x}} \equiv\left(\mathbf{A}^{T} \mathbf{A}\right)^{-1}$ is the covariance matrix of solution $\hat{\mathbf{x}}$. The errors of the retrieved columns are estimated as follows (Press et al., 1992): $\sigma_{\hat{V}_{j}}=\sqrt{\left(\mathbf{C}_{\mathbf{x}}\right)_{j j} \times \sum_{i} \mathbf{R E S}_{i}^{2} /(m-n)}$, where $\left(\mathbf{C}_{\mathbf{x}}\right)_{j j}$ is the $j$-th diagonal element of the covariance matrix, $m$ is the number of spectral points in the fitting window and $n$ is the number of linear fit parameters.

In order to avoid time-consuming on-line radiative transfer simulations, a fast look-up table scheme has been implemented. The pre-computed spectral radiances and their derivatives (e.g., with respect to trace gas concentration and temperature profile changes) depend on solar zenith angle, surface elevation (pressure), surface albedo, and water vapour amount (to consider possible non-linearities caused by the high variability of atmospheric water vapour). For carbon dioxide a single (constant) vertical profile is used for the retrieval to avoid that the measurements are influenced by variations artificially introduced by the retrieval method. These profiles $\left(\mathrm{CO}_{2}\right.$ mixing ratio, temperature, pressure) along with the vertical column averaging kernels, can be obtained from the WFM-DOAS web site http://www.iup.uni-bremen.de/sciamachy/NIR_NADIR_ WFM_DOAS/index.html. The $\mathrm{CO}_{2}$ columns are retrieved using a small spectral fitting window in the near infrared (1558-1594 nm) located in SCIAMACHY channel 6, whereas oxygen, retrieved in order to derive the columnaveraged $\mathrm{CO}_{2}$ dry air mole fraction, is retrieved from a spectrally distant fitting window $\left(755-775 \mathrm{~nm}, \mathrm{O}_{2}\right.$ A-band) in SCIAMACHY channel 4. As an example, Fig. 3 shows the year 2003 average of the total columns of both gases (for a detailed discussion see Sect. 5).

The main differences between the previous version, version 0.4, and the new version, version 1.0, are the following:

(i) Better consideration of albedo variability: The surface albedo is specifically retrieved in each fitting window separately to consider its wavelength dependence in combination with an extended look-up table. The wavelength dependent surface albedo retrieval is based on comparing the measured sun-normalized radiance at selected wavelengths, in a transparent region of each fitting window where no significant gaseous or particulate absorptions occur, to pre-calculated radiances for different surface albedos. The retrieved surface albedo is used to account for the dependence of the top-ofatmosphere radiance on the surface albedo. In comparison, for computational simplicity, the previous WFM-DOAS versions used a constant wavelength independent surface albedo of 0.1. The extended look-up table includes surface albedos of $0.03,0.1$, and 0.3 and an interpolation/extrapolation scheme is used to obtain the radiance and its derivatives for the retrieved surface albedo in each fitting window.

(ii) Better consideration of surface elevation changes: An extended look-up table scheme for surface elevation (pres- sure) has been implemented. The previous versions of WFMDOAS used pre-calculated radiances and derivatives for surface elevations of $0 \mathrm{~km}, 1 \mathrm{~km}, 2 \mathrm{~km}$, and $3 \mathrm{~km}$ in combination with a simple next neighbour approach. Now an extended data base covering also an altitude of $4 \mathrm{~km}$ is used in combination with an interpolation/extrapolation scheme to determine the radiance and its derivatives appropriate for the average surface elevation (pressure) of each ground scene. This significantly reduces the associated error of the retrieved columns (as discussed in detail below) which could be as large as a few percent in version 0.4 (Buchwitz et al., 2005a).

(iii) Improved spectroscopy: Update of the spectroscopic data to HITRAN 2004 (Rothman et al., 2005). The previous version was based on the line parameters for $\mathrm{CO}_{2}, \mathrm{O}_{2}$, and $\mathrm{H}_{2} \mathrm{O}$ described in HITRAN 2000/2001 (Rothman et al., 2003).

(iv) Improved calibration: Usage of newly calibrated Level 1-Files (spectra) version 5. The SCIAMACHY Level 1 product is a geophysical product, describing the measured spectral radiance in units of photons $/ \mathrm{s} / \mathrm{cm}^{2} / \mathrm{nm} /$ steradiant as a function of wavelength in units of nanometers. Our previous versions data products were based on the Level 1 version 4 data product. One significant error had been identified in the previous WFM-DOAS data product due to calibration problems of the version 4 spectra (Buchwitz et al., 2006a): systematically underestimated $\mathrm{CO}_{2}$ columns which have been corrected to first order by scaling with the constant factor 1.27. Using the new Level 1 product this source of error is now negligible.

Another problem of $\mathrm{XCO}_{2} \mathrm{v} 0.4$ were systematically overestimated $\mathrm{O}_{2}$ columns which have been corrected by scaling with the constant factor 0.85 . The scaling factors for the $\mathrm{CO}_{2}$ and $\mathrm{O}_{2}$ columns used in the previous WFM-DOAS version $0.4 \mathrm{XCO}_{2}$ data product were chosen such that the $\mathrm{CO}_{2}$ and $\mathrm{O}_{2}$ columns were within experimental error close to their expected value of about $8 \times 10^{21}$ molecules $/ \mathrm{cm}^{2}$ and $4.5 \times 10^{24}$ molecules $/ \mathrm{cm}^{2}$, respectively, for cloud-free scenes with a surface elevation corresponding to sea level. The need for an $\mathrm{O}_{2}$ column scaling factor was removed by the improved treatment of surface albedo in WFM-DOAS version 1.0. In the previous version 0.4 a constant albedo of 0.1 was assumed and a surface spectral reflectance weighting function (derivative) was included for the $\mathrm{O}_{2}$ column fit to minimize errors related to the variability of the surface spectral reflectance. The new approach removes the need for a weighting function for surface albedo in WFMDv1.0. The new version WFM-DOAS 1.0 yields the expected values for the $\mathrm{CO}_{2}$ and $\mathrm{O}_{2}$ columns without scaling.

\subsection{Computation of column-averaged $\mathrm{CO}_{2}$ dry air mole fractions}

For carbon dioxide we derive column-averaged dry air mole fractions by normalizing the $\mathrm{CO}_{2}$ columns with the simultaneously retrieved oxygen columns retrieved from the $\mathrm{O}_{2}$ 
A-band. Oxygen is an accurate proxy for the air column because its mole fraction is well known and has negligibly small variations. The column-averaged mole fraction $\mathrm{XCO}_{2}$ is computed as follows:

$$
\mathrm{XCO}_{2}=\frac{\mathrm{CO}_{2}^{\mathrm{col}}}{\left(\mathrm{O}_{2}^{\mathrm{col}} / \mathrm{O}_{2}^{\mathrm{mf}}\right)},
$$

where $\mathrm{CO}_{2}^{\text {col }}$ is the retrieved absolute $\mathrm{CO}_{2}$ column (in molecules $/ \mathrm{cm}^{2}$ ), $\mathrm{O}_{2}^{\text {col }}$ is the retrieved absolute $\mathrm{O}_{2}$ column (in molecules $/ \mathrm{cm}^{2}$ ), and $\mathrm{O}_{2}^{\mathrm{mf}}$ is the assumed (column-averaged) mole fraction of $\mathrm{O}_{2}$ used to convert the $\mathrm{O}_{2}$ column into a corresponding dry air column and is equal to 0.2095 . The resulting $\mathrm{XCO}_{2}$ for the time period 2003-2005 is shown in Fig. 4 and will be discussed in Sect. 5 .

\subsection{Quality flags}

In order to separate out ground scenes affected by clouds or poor spectral fits, quality flags marking successful measurements are set for each single measurement (i.e., for each observed ground scene).

For the column-averaged dry air mole fraction of carbon dioxide, measurements satisfying the following criteria are classified as being good by the WFM-DOAS retrieval and are subsequently used for the analysis described in this manuscript:

- The root-mean-square (RMS) of the fit residuum (relative difference between measurement and model after the fit) in the $\mathrm{CO}_{2}$ fitting window has to be less than $0.25 \%$.

- The RMS of the fit residuum in the $\mathrm{O}_{2}$ fitting window has to be less than $2 \%$.

- The $\mathrm{CO}_{2}$ column fit error has to be less than $2.5 \%$.

- The observed scene has to be nearly cloud free. Cloud contaminated ground scenes are identified using a threshold algorithm based on sub-pixel information provided by the SCIAMACHY Polarization Measurement Device (PMD) channel 1 detecting enhanced backscatter in the UV as described in Buchwitz et al. (2005a). In addition it is required that the retrieved $\mathrm{O}_{2}$ column has to be larger than $90 \%$ of the assumed a-priori $\mathrm{O}_{2}$ column (determined from surface elevation and the known mixing ratio of $\mathrm{O}_{2}$ ).

- The SZA has to be less than $75^{\circ}$ (as the signal gets weaker for high SZAs and the sensitivity to changes of the absorber amount in the boundary layer decreases with increasing SZA (saturation)).

- The ground pixel must be over land (as the signal-tonoise ratio is typically significantly worse over water).
- The ground pixel must be a forward scan pixel (as the horizontal resolution of the backward scan pixel is four times larger (typically $240 \mathrm{~km}$ across track compared to $60 \mathrm{~km}$ for the forward scan).

- The surface elevation has to be less than $5 \mathrm{~km}$ as higher altitudes are not covered by the current look-up table.

In addition, we filter for strong aerosol contamination as will be described in the next section.

\subsection{Aerosol filtering}

Unaccounted variability of aerosols and clouds (including cirrus) in the retrieval is an important error source for $\mathrm{CO}_{2}$ measurements from space (Tolton and Plouffe, 2001; O'Brien and Rayner, 2002; Kuang et al., 2002; Dufour and Bréon, 2003; Buchwitz and Burrows, 2004; Buchwitz et al., 2005a; Christi and Stephens, 2004; Mao and Kawa, 2004; Houweling et al., 2005; van Diedenhoven et al., 2005; Barkley et al., 2006a; Aben et al., 2006; Bril et al., 2007) as aerosols are highly variable and their optical properties (e.g., vertical profiles of phase function, extinction and scattering coefficients) are not known for each scene observed from satellite. This results in aerosol and cloud related errors which are difficult to quantify. Figure 5 illustrates that unrealistically enhanced values appearing in the retrieved $\mathrm{CO}_{2}$ mole fraction are correlated with enhanced levels of absorbing aerosols as retrieved by Earth Probe/TOMS (Herman et al., 1997) obtained from http://toms.gsfc.nasa.gov/. Aerosol types detected by the TOMS AAI include desert dust, smoke and volcanic ash located at least $2 \mathrm{~km}$ above the surface. During June 2003 the Absorbing Aerosol Index (AAI) is high over the Sahara due to desert dust storms. During this month the SCIAMACHY carbon dioxide data product also shows high values and good correlation with the aerosol index. During November AAI is low and the SCIAMACHY $\mathrm{XCO}_{2}$ is not enhanced. This comparison shows that the retrieved carbon dioxide mole fraction can exhibit large (few percent) errors in case of strong desert dust storms. To remove aerosol contaminated retrieved $\mathrm{XCO}_{2}$ for cases of high aerosol load, primarily over deserts (mainly Sahara), we apply an additional quality criterion for the global analysis of $\mathrm{XCO}_{2}$ by rejecting ground scenes where the TOMS aerosol index is greater than a specific threshold. Figure 6 illustrates the AAI filtering.

In this context it is interesting to investigate whether the effect of overestimated $\mathrm{CO}_{2}$ mole fractions in case of strong desert dust storms is dominated by errors of the $\mathrm{CO}_{2}$ or the $\mathrm{O}_{2}$ column. Figure 7 shows the $\mathrm{XCO}_{2}$ data product over the Sahara obtained using the simultaneously retrieved $\mathrm{O}_{2}$ column compared to that derived using model $\mathrm{O}_{2}$ columns computed from surface pressure obtained from meteorological analysis:

$\mathrm{O}_{2}(\mathrm{mod})=\frac{\mathrm{p}(\mathrm{mod})}{1013 \mathrm{hPa}} \cdot 4.51 \cdot 10^{24} \frac{\mathrm{molec}}{\mathrm{cm}^{2}}$ 
Assuming that the computed oxygen column obtained from meteorological (ECMWF) surface pressure is accurate, it can be concluded that the enhanced $\mathrm{CO}_{2} / \mathrm{O}_{2}(\mathrm{mod})$ ratio over the Sahara must be due to an (at least relative to the surrounding areas) overestimated $\mathrm{CO}_{2}$ column, which is consistent with the findings of Houweling et al. (2005) who showed by simulated retrievals that aerosol-induced path length enhancements can explain unrealistically enhanced carbon dioxide columns in the presence of desert dust.

Figure 7 additionally shows that the $\mathrm{CO}_{2}$ column error cancels partially when computing the ratio with the measured $\mathrm{O}_{2}$ columns. Therefore it can be concluded that aerosols due to strong desert dust storms are causing an overestimation of both the $\mathrm{CO}_{2}$ and $\mathrm{O}_{2}$ columns but affecting $\mathrm{CO}_{2}$ to a greater extent so that the errors do not cancel completely in $\mathrm{XCO}_{2}$. As can be seen, the $\mathrm{CO}_{2}$ field is smoothest (and probably most realistic) if the aerosol filter is applied and if the retrieved $\mathrm{CO}_{2}$ is normalized using the retrieved $\mathrm{O}_{2}$ columns due to better cancellation of errors when the retrieved $\mathrm{O}_{2}$ is used to compute $\mathrm{XCO}_{2}$. We therefore conclude that the $\mathrm{XCO}_{2}$ shown in the bottom left panel is the most accurate of the four $\mathrm{XCO}_{2}$ data sets shown here.

As WFM-DOAS v1.0 uses a single constant aerosol scenario and aerosol variability is only accounted for to first order by the inclusion of a low order polynomial in the WFMDOAS fit, perceptible deviations under extreme conditions are expected (Buchwitz and Burrows, 2004; Buchwitz et al., 2005a). Other groups use somewhat different but also highly simplified approaches to deal with aerosol variability. For example in FSI/WFM-DOAS (Barkley et al., 2006a,b,c, 2007) three "climatological" aerosol scenarios (maritime, rural, and urban) are used (instead of one as in WFM-DOAS) depending on the location of the satellite footprint. This approach is not considered to be superior compared to our approach as it also does not take aerosol variability fully into account and might introduce additional complications such as discontinuities of the retrieved $\mathrm{CO}_{2}$ near cities and coast lines.

Future studies will show to what extent aerosol related errors can be reduced by taking aerosol variability better into account in the radiative transfer used to determine $\mathrm{XCO}_{2}$ but at present we only identify aerosols and filter the data to remove strongly aerosol contaminated scenes.

\section{Error analysis}

The retrieved carbon dioxide and oxygen vertical columns exhibit a random error due to instrument noise depending on the signal-to-noise ratio and thus on surface albedo and characteristics of the detector of the respective channel. This results in a single measurement precision of about $\sim 1 \%$ for the retrieved $\mathrm{CO}_{2}$ columns and because of the much better signal-to-noise ratio in the $\mathrm{O}_{2} \mathrm{~A}$ band spectral region (around $760 \mathrm{~nm}$; SCIAMACHY channel 4) in a considerably smaller random error of the $\mathrm{O}_{2}$ column of about $\sim 0.3 \%$. Hence, the
Table 1. Results of the error analysis for different constant albedos performed by applying WFM-DOAS to simulated SCIAMACHY spectra. The results are valid for a solar zenith angle of $50^{\circ}$ and a surface elevation corresponding to sea level.

\begin{tabular}{crrr}
\hline Albedo & $\begin{array}{r}\mathrm{CO}_{2} \text { column } \\
\text { error [\%] }\end{array}$ & $\begin{array}{r}\mathrm{O}_{2} \text { column } \\
\text { error [\%] }\end{array}$ & $\begin{array}{r}\mathrm{XCO}_{2} \\
\text { error [\%] }\end{array}$ \\
\hline 0.003 & 0.63 & 0.89 & -0.26 \\
0.03 & -0.01 & 0.01 & -0.02 \\
0.05 & -0.05 & -0.02 & -0.03 \\
0.08 & -0.04 & -0.01 & -0.03 \\
0.10 & -0.01 & 0.01 & -0.02 \\
0.15 & -0.13 & -0.16 & 0.03 \\
0.20 & -0.13 & -0.18 & 0.05 \\
0.30 & -0.01 & 0.01 & -0.02 \\
0.40 & 0.18 & 0.31 & -0.13 \\
\hline
\end{tabular}

upper bound of the theoretical precision of the $\mathrm{XCO}_{2}$ can be estimated to be slightly larger than $1 \%$ using radiative transfer simulations and the instrument's signal-to-noise performance. To estimate the single ground pixel retrieval precision of the real in-orbit measurements we determined for several locations daily standard deviations of the retrieved $\mathrm{XCO}_{2}$ (because of the orbit geometry this basically corresponds to the standard deviation of all the data from a single overpass at around 10:00 a.m. local time). We averaged the daily standard deviations determined from all the SCIA$\mathrm{MACHY} \mathrm{XCO}_{2}$ retrievals at a given location for all days where at least 10 measurements pass the quality filter in a radius of $350 \mathrm{~km}$ around that location. This average $\mathrm{XCO}_{2}$ standard deviation can be interpreted as an upper limit of the single ground pixel retrieval precision (as it is also influenced by the variability of atmospheric $\mathrm{CO}_{2}$ ). This analysis was performed for Park Falls (USA), Bremen (Germany), and Darwin (Australia) providing a consistent estimate of the precision error of about 5-6 ppm, respectively, which corresponds approximately to $1.5 \%$ and is therewith close to the expected theoretical value.

In addition to instrument noise there are several other error sources such as errors resulting from the variability of temperature and water vapour profiles, aerosols, clouds, and surface spectral reflectivity. Most of these errors were already quantified for earlier versions of WFM-DOAS (Buchwitz and Burrows, 2004; Buchwitz et al., 2005a). Because of the improved albedo treatment in version 1.0, with albedo retrieval and the extended look-up table interpolation/extrapolation method, the albedo related $\mathrm{XCO}_{2}$ errors shown in Table 1, which could be as large as a few percent in the previous version, are now significantly reduced and essentially negligible (absolute value $\lesssim 0.1 \%$ ) for typical albedos assumed to be wavelength independent in a given spectral fitting window. Table 2 shows the retrieval errors for different natural surface types taking the full spectral albedo 
Table 2. As Table 1 but for the spectral albedos of natural surface types shown in Fig. 8 taken from the ASTER and USGS spectral libraries.

\begin{tabular}{lrrr}
\hline Surface type & $\begin{array}{r}\mathrm{CO}_{2} \text { column } \\
\text { error [\%] }\end{array}$ & $\begin{array}{r}\mathrm{O}_{2} \text { column } \\
\text { error [\%] }\end{array}$ & $\begin{array}{r}\mathrm{XCO}_{2} \\
\text { error [\%] }\end{array}$ \\
\hline Sand (Entisol) & 0.13 & 0.03 & 0.10 \\
Soil (Mollisol) & 0.41 & 0.13 & 0.28 \\
Deciduous (Aspen) & 0.22 & 0.17 & 0.05 \\
Conifers-Meadow & -0.01 & 0.11 & -0.12 \\
Rangeland & -0.11 & -0.04 & -0.07 \\
Open Ocean & 0.06 & 0.16 & -0.10 \\
Medium Snow & 0.37 & 1.83 & -1.43 \\
\hline
\end{tabular}

dependence (also within the small spectral fitting windows) into account. As can be seen, the retrieval errors are well below one percent for typical surfaces with the exception of snow where the very high albedo (close to 1 ) in the $\mathrm{O}_{2}$ fitting window leads to a somewhat higher error. However, snowand ice-covered surfaces are typically filtered out as a sideeffect of the PMD cloud detection. Otherwise an observable $\mathrm{XCO}_{2}$ underestimation would be expected. The albedo related errors for surface types with albedos higher than 0.3 in at least one fitting window can be further reduced by adding additional albedos to the reference spectra in the future.

The accuracy of the corresponding albedo retrieval for typical scenes unaffected by clouds or strong aerosol contamination is estimated to be better than $0.5 \%$ based on the simulated measurements for constant and spectral albedos discussed above. The globally retrieved albedos from real SCIAMACHY data for the different fitting windows depicted in Fig. 2 exhibit a high correlation with the land cover type being consistent with the independently measured spectral albedos for different natural surface types shown in Fig. 8. Although the albedo retrieval errors for real data might be somewhat higher than estimated from simulations due to possible interferences with clouds or aerosols we are confident that the retrieved values are reasonable because of the mentioned global comparison with landcover and spectral libraries.

The $\mathrm{XCO}_{2}$ retrieval error due to surface elevation (mean surface pressure) variations caused by the pressure dependence of the absorption cross sections is also significantly reduced due to better consideration of surface elevation changes dropping for example from $2.5 \%$ in version 0.4 for a surface elevation of $400 \mathrm{~m}$ (Buchwitz et al., 2005a) to $0.3 \%$ in version 1.0 by using the new altitude interpolation/extrapolation scheme. This scheme enables getting rid of the discontinuities of the retrieval error of the previous nearest neighbour approach at surface elevations right between two reference values contained in the look-up table (namely at $0.5 \mathrm{~km}, 1.5 \mathrm{~km}, 2.5 \mathrm{~km}$, etc.).

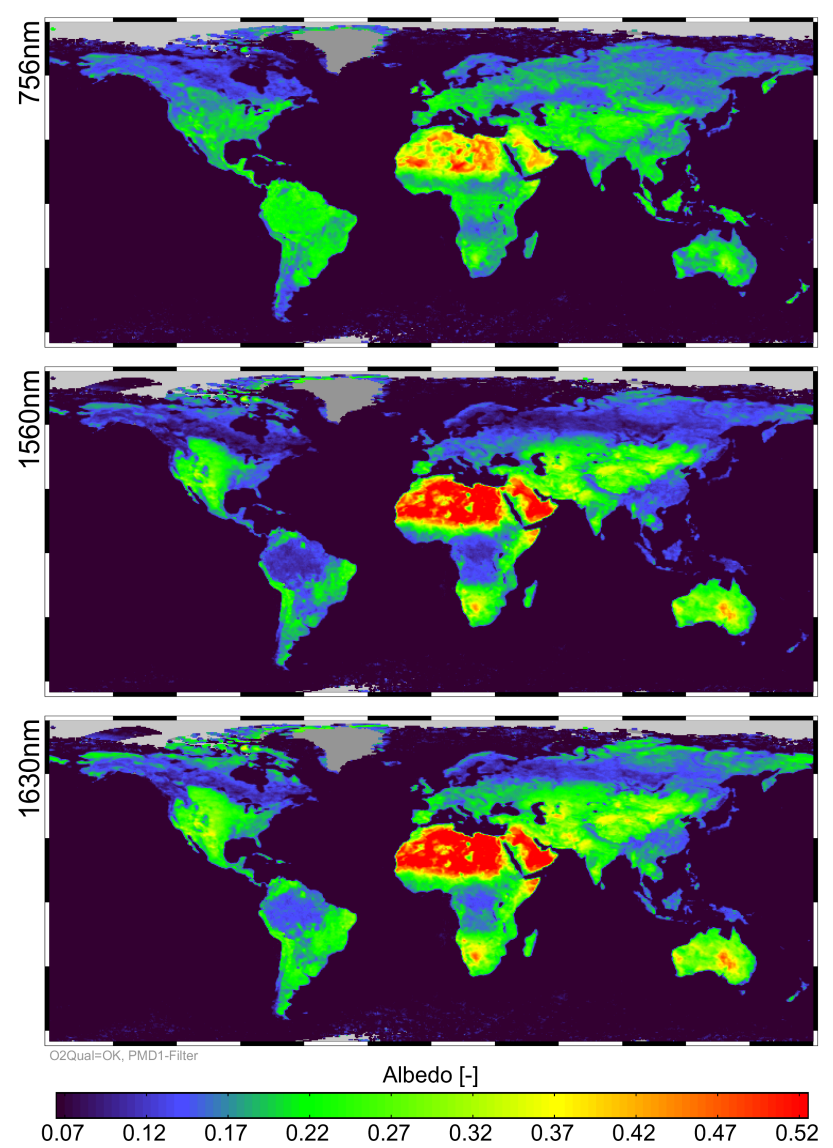

Fig. 2. Albedos retrieved in transparent regions of the $\mathrm{O}_{2}, \mathrm{CO}_{2}$, and $\mathrm{CH}_{4}$ fitting windows, respectively, considering only cloud free (and snow and ice free) ground scenes during 2003 and $2004\left(0.5^{\circ} \times 0.5^{\circ}\right.$ gridded). Different surface types are clearly distinguishable.

To estimate the retrieval error due to aerosols several aerosol scenarios have been defined (see Tables 3 and 4), the default scenario used for the look-up table generation being characterized as follows: Maritime aerosol in the boundary layer (BL), tropospheric visibility and humidity $23 \mathrm{~km}$ and $80 \%$, respectively, background stratospheric, and normal mesospheric conditions. Besides the rather extreme scenario with strongly enhanced aerosol in the boundary layer (urban aerosol in the BL with visibility of only $2 \mathrm{~km}$ and relative humidity of $99 \%$ ), three additional more typical scenarios are considered (using Mie phase function instead of the Henyey-Greenstein parameterization used for the LUT default scenario): (i) "OPAC background" consists of continental relatively clean aerosol in the BL and the free troposphere (99.998\% water soluble), (ii) "OPAC urban" has continental polluted aerosol in the boundary layer $(31.399 \%$ water soluble and $68.6 \%$ soot) and continental average aerosol $(45.79 \%$ water soluble and $54.2 \%$ soot) in the free troposphere, and (iii) "OPAC desert" consists of desert aerosol 
Table 3. Aerosol scattering (ASOD) and aerosol absorption vertical optical depth (AAOD) in the $\mathrm{O}_{2}$ and $\mathrm{CO}_{2}$ fitting windows for the aerosol scenarios used in the error analysis. For comparison the Rayleigh scattering vertical optical depth (RSOD) has also been included.

\begin{tabular}{lccc}
\hline Aerosol scenario & & $756 \mathrm{~nm}$ & $1560 \mathrm{~nm}$ \\
\hline Look-up table default & ASOD: & 0.24669 & 0.17369 \\
& AAOD: & 0.00291 & 0.00307 \\
OPAC background & ASOD: & 0.09353 & 0.02211 \\
& AAOD: & 0.00315 & 0.00293 \\
OPAC urban & ASOD: & 0.16420 & 0.04794 \\
\multirow{2}{*}{ OPAC desert } & AAOD: & 0.02373 & 0.01411 \\
\multirow{2}{*}{ Extreme in BL } & ASOD: & 0.22740 & 0.17568 \\
& AAOD: & 0.01406 & 0.00419 \\
& ASOD: & 2.12661 & 0.91676 \\
& AAOD: & 0.13324 & 0.07892 \\
\hline \multirow{2}{*}{} & RSOD: & 0.02674 & 0.00145 \\
\hline
\end{tabular}

(93.19\% mineral (nucleation mode) and $6.81 \%$ mineral (accumulation mode)) in the boundary layer and the continental clean aerosol type in the free troposphere. For these three scenarios the sensitivity to aerosols is less than $1 \%$. However, in extreme situations (e.g., very high boundary layer aerosol) the error can be as high as about $5 \%$ because the sensitivity in the $\mathrm{O}_{2}$ A-band is significantly larger than in the NIR in these cases. Therefore strongly aerosol contaminated scenes are filtered out as described in Sect. 3.4. Future research will further examine aerosol related errors taking a broader subset of the myriad of imaginable aerosol scenarios and associated optical properties into account, e.g., internally mixed aerosol types.

The vertical column retrieval error due to (undetected) subvisual cirrus clouds is roughly estimated by modeling a scattering layer of $1 \mathrm{~km}$ vertical extent centered at a height of $12 \mathrm{~km}$ with an assumed scattering vertical optical depths independent of wavelength which is reasonable because the particle size is much larger than the wavelength. The results for different vertical optical depths and surface albedos are listed in Table 5 showing that such a scattering layer typically leads to an considerable underestimation of the oxygen vertical columns increasing with increasing optical depth of the layer and decreasing albedo. Hence, the resulting $\mathrm{XCO}_{2}$ overestimation can become rather large in the case of cirrus clouds not detected by the quality filter especially over dark surfaces.

In order to examine the sensitivity to the variability of temperature, pressure, and trace gas vertical profiles, simulated spectra for several model atmospheres (extracted from MODTRAN; Berk et al., 1998) have been generated while the WFM-DOAS look-up table is based on the US Standard Atmosphere. The analysed atmospheres differ from the US
Table 4. Results of the error analysis for various aerosol scenarios. The results are valid for an albedo of 0.1 , a solar zenith angle of $50^{\circ}$ and a surface elevation corresponding to sea level.

\begin{tabular}{lrrr}
\hline Aerosol scenario & $\begin{array}{r}\mathrm{CO}_{2} \text { column } \\
\text { error [\%] }\end{array}$ & $\begin{array}{r}\mathrm{O}_{2} \text { column } \\
\text { error [\%] }\end{array}$ & $\begin{array}{r}\mathrm{XCO}_{2} \\
\text { error [\%] }\end{array}$ \\
\hline OPAC background & -0.73 & 0.26 & -0.99 \\
OPAC urban & -0.70 & -0.05 & -0.65 \\
OPAC desert & -0.14 & -0.49 & 0.35 \\
Extreme in BL & -1.16 & -6.50 & 5.71 \\
\hline
\end{tabular}

Standard Atmosphere with respect to temperature, pressure and water vapour profiles; the resulting retrieval errors are shown in Table 6. As can be seen, the $\mathrm{XCO}_{2}$ errors are less than $1 \%$ for all cases.

The investigation of errors resulting from profile variability has been extended focussing on an error analysis relevant for the $\mathrm{CO}_{2}$ seasonal cycle. To specify the errors originating from unconsidered variability of temperature and trace gas profiles (WFM-DOAS uses a single profile in each case for the retrieval), simulated spectra have been generated using ECMWF temperature and water vapour profiles as well as carbon dioxide profiles from NOAA's CarbonTracker model (described below). Park Falls was chosen as a reference location for this study because it is representative for northern hemispheric mid-latitudes and because the choice of this site is helpful in estimating the error of the retrieved $\mathrm{XCO}_{2}$ seasonal cycle when comparing with the Park Falls FTS (see Sect. 5).

As one can see in Fig. 9, the $\mathrm{CO}_{2}$ and $\mathrm{O}_{2}$ vertical column errors due to temperature profile variability cancel to a large extent when calculating the $\mathrm{CO}_{2}$ to $\mathrm{O}_{2}$ column ratio, i.e., the $\mathrm{CO}_{2}$ mole fraction, because both absorption bands respond similar to temperature changes. The water vapour profile related error is negligible because the spectral fitting windows have been selected such that interference with water vapour absorption is small. Additionally a weighting function (radiance derivative) for water absorption is included in the $\mathrm{CO}_{2}$ fit and an iteration regarding water vapour is implemented in the algorithm further minimizing this error. From the three error sources investigated, the dominating error is the carbon dioxide vertical profile variability error (being defined as the deviation of the retrieved $\mathrm{XCO}_{2}$ from the true $\mathrm{XCO}_{2}$ ) which is about $0.8 \%$ peak-to-peak (note that this error can be reduced if the $\mathrm{CO}_{2}$ vertical profile is (approximately) known by taking into account the SCIAMACHY WFM-DOAS $\mathrm{CO}_{2}$ retrieval averaging kernels, which characterize the altitude sensitivity of the $\mathrm{CO}_{2}$ retrievals). When all three error sources are considered together, the total $\mathrm{XCO}_{2}$ retrieval error is $1.0 \%$ peak-to-peak. These findings are consistent with a similar error analysis for WFM-DOAS performed by Barkley et al. (2006a) restricted to $\mathrm{CO}_{2}$ total column retrieval. 
Table 5. Results of the error analysis for undetected subvisual cirrus clouds at $12 \mathrm{~km}$ with different assumed scattering optical depths (SOD) for albedos 0.1 and 0.3 . The results are valid for a solar zenith angle of $50^{\circ}$, and a surface elevation corresponding to sea level.

\begin{tabular}{lrrr}
\hline Cloud scenario & $\begin{array}{r}\mathrm{CO}_{2} \text { column } \\
\text { error [\%] }\end{array}$ & $\begin{array}{r}\mathrm{O}_{2} \text { column } \\
\text { error [\%] }\end{array}$ & $\begin{array}{r}\mathrm{XCO}_{2} \\
\text { error [\%] }\end{array}$ \\
\hline Albedo 0.1: & & & \\
Subvisual Cirrus (OD 0.01) & -0.58 & -3.12 & 2.62 \\
Subvisual Cirrus (OD 0.02) & -0.78 & -6.09 & 5.65 \\
Subvisual Cirrus (OD 0.03) & -0.89 & -8.91 & 8.80 \\
\hline Albedo 0.3: & & & \\
Subvisual Cirrus (OD 0.01) & 0.18 & -1.17 & 1.37 \\
Subvisual Cirrus (OD 0.02) & 0.71 & -2.31 & 3.09 \\
Subvisual Cirrus (OD 0.03) & 1.33 & -3.41 & 4.91 \\
\hline
\end{tabular}

Table 6. Retrieval errors resulting from applying WFM-DOAS to various model atmospheres valid for an albedo of 0.1 , a solar zenith angle of $50^{\circ}$, and a surface elevation corresponding to sea level. The analysed atmospheres differ from the US Standard Atmosphere used as reference with respect to temperature, pressure and water vapour profiles.

\begin{tabular}{lrrr}
\hline Atmosphere & $\begin{array}{r}\mathrm{CO}_{2} \text { column } \\
\text { error [\%] }\end{array}$ & $\begin{array}{r}\mathrm{O}_{2} \text { column } \\
\text { error [\%] }\end{array}$ & $\begin{array}{r}\mathrm{XCO}_{2} \\
\text { error [\%] }\end{array}$ \\
\hline Sub-artic summer & 0.04 & -0.38 & 0.42 \\
Sub-artic winter & 0.17 & 0.67 & -0.50 \\
Mid-latitude summer & -0.15 & -0.55 & 0.40 \\
Mid-latitude winter & 0.47 & 0.66 & -0.19 \\
Tropical & -0.54 & -0.68 & 0.14 \\
\hline
\end{tabular}

\section{Discussion of the multi-year $\mathrm{XCO}_{2}$ data set}

All SCIAMACHY spectra (Level $1 \mathrm{~b}$ version 5 converted to Level 1c by the ESA SciaL1C tool using the standard calibration) for the years 2003, 2004, and 2005 which have been made available by ESA/DLR, have been processed using the improved retrieval algorithm WFM-DOAS version 1.0.

\section{1 $\mathrm{CO}_{2}$ yearly averages and annual increase}

Figure 3 shows, as an example, the $\mathrm{CO}_{2}$ and $\mathrm{O}_{2}$ total column annual averages for the year 2003. It can be seen that the spatial variations are very similar $(r=0.98)$ because both gases are long-lived and therefore well mixed in the atmosphere; hence the columns are primarily reflecting Earth's topography. The small $\mathrm{CO}_{2}$ source and sink signals we are primarily interested in are hidden in the tiny differences between the $\mathrm{CO}_{2}$ columns and the $\mathrm{O}_{2}$ columns. These signals can be made visible by computing $\mathrm{XCO}_{2}$, i.e., the column-averaged dry air mole fraction of $\mathrm{CO}_{2}$, as described in Section 3.2.

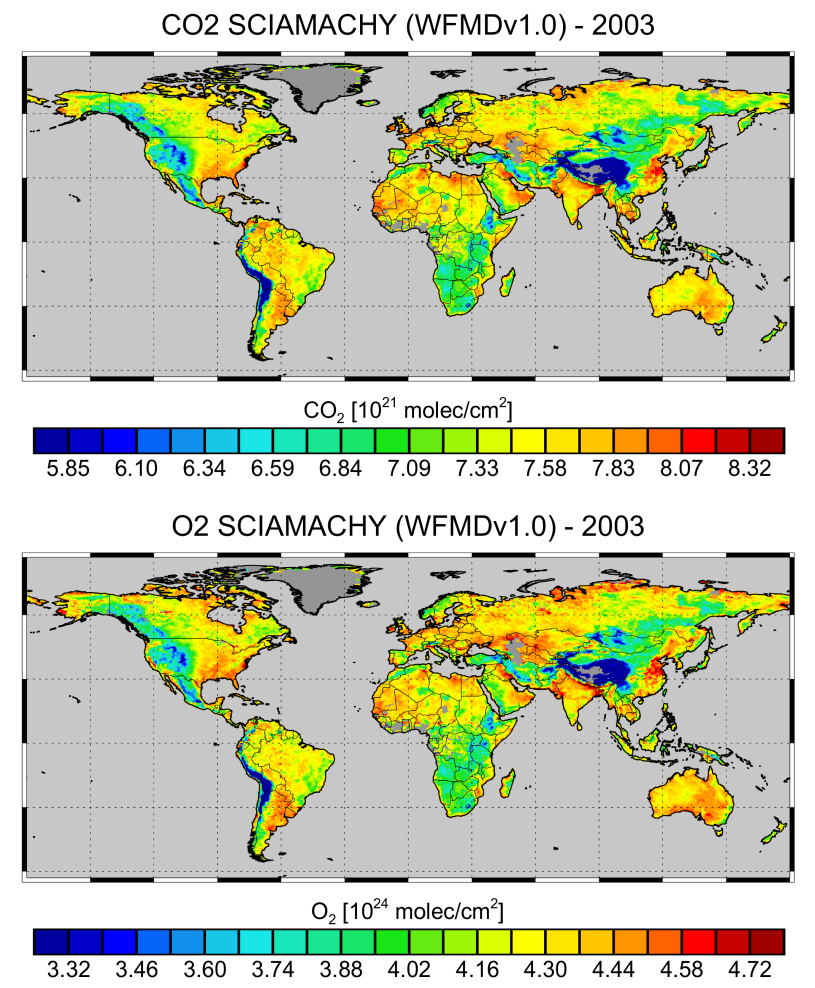

Fig. 3. $\mathrm{CO}_{2}$ (top) and $\mathrm{O}_{2}$ (bottom) total vertical columns for the year 2003 as retrieved from SCIAMACHY $\left(0.5^{\circ} \times 0.5^{\circ}\right.$ gridded $)$. Both gases are long-lived and therefore well mixed in the atmosphere; hence the columns of the two gases are well correlated $(r=0.98)$ and the spatial pattern primarily reflect the Earth's topography.

The corresponding SCIAMACHY $\mathrm{XCO}_{2}$ for 2003 is shown in Fig. 4. For all three quantities derived from SCIAMACHY, the $\mathrm{CO}_{2}$ and $\mathrm{O}_{2}$ columns and $\mathrm{XCO}_{2}$, the same filtering criteria have been applied. 

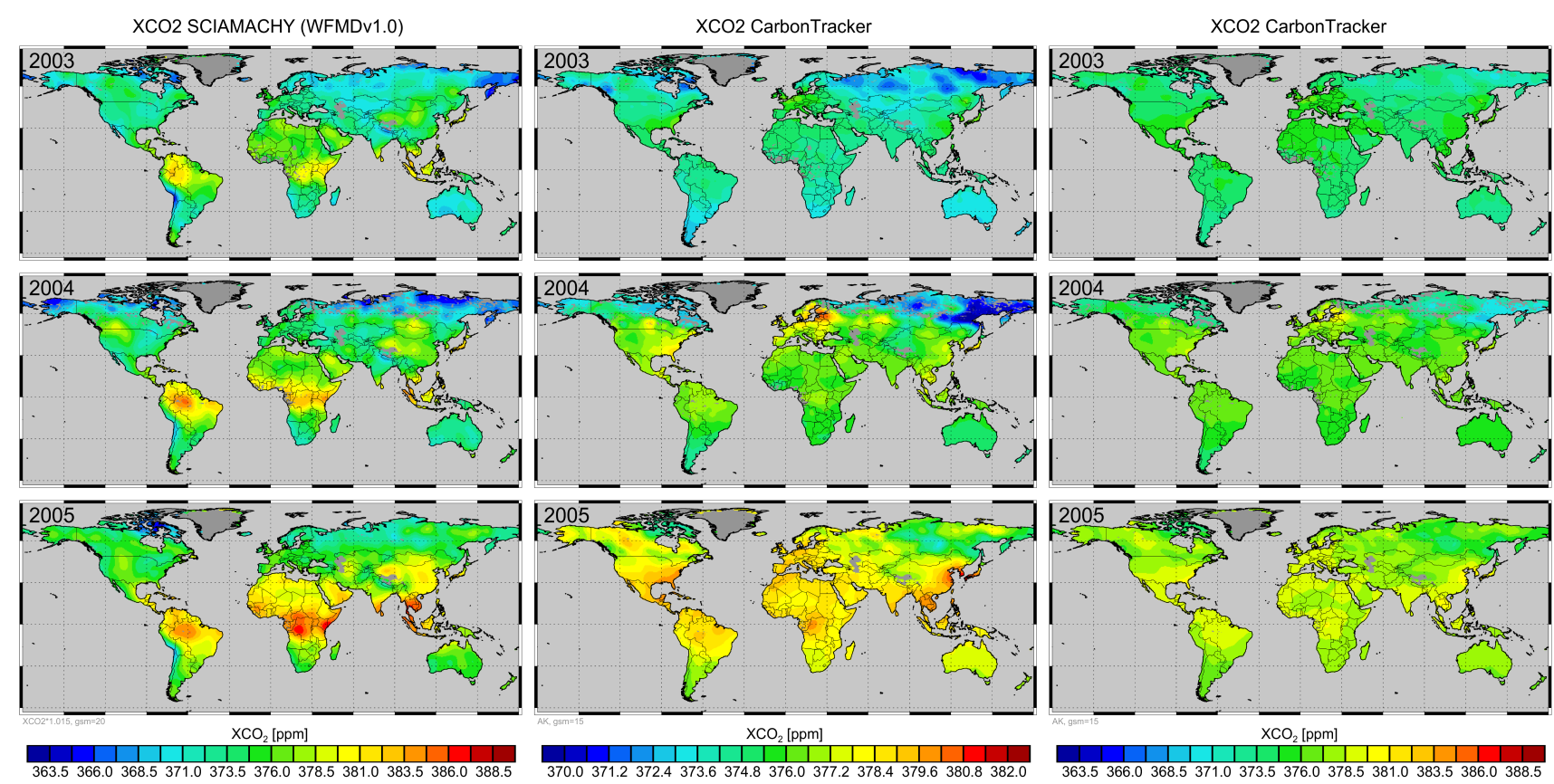

Fig. 4. Three years of SCIAMACHY carbon dioxide column-averaged dry air mole fractions (left) as retrieved by WFM-DOAS version 1.0 (WFMDv1.0) compared to NOAA's CarbonTracker (middle) sampled as SCIAMACHY measures using an appropriate color scale. The color scales are different for SCIAMACHY and CarbonTracker to consider the higher variability of the $\mathrm{SCIAMACHY} \mathrm{XCO}_{2}( \pm 12.5 \mathrm{ppm})$ compared to CarbonTracker ( $\pm 6.0 \mathrm{ppm})$. The right column also shows the CarbonTracker $\mathrm{XCO}_{2}$ but using the same color scale as has been used for the satellite data. The SCIAMACHY $\mathrm{CO}_{2}$ shown here has been aerosol filtered using TOMS/Earth Probe Absorbing Aerosol Index (AAI) (see main text for details). The data have been gridded on a $0.5^{\circ} \times 0.5^{\circ}$ grid and smoothed using Gaussian smoothing functions of width $20\left(10^{\circ}\right)$ for SCIAMACHY and $15\left(7.5^{\circ}\right)$ for CarbonTracker (the width are different to consider the lower resolution of the original CarbonTracker data compared to SCIAMACHY).

The resulting annual composite averages for $\mathrm{XCO}_{2}$, which meet the classification "good" defined above, are shown in Fig. 4 (left hand side panels). A significant part of the $\mathrm{CO}_{2}$ spatial variations shown in Fig. 4 result from the irregular sampling of the SCIAMACHY $\mathrm{XCO}_{2}$. For example, the mid and high latitudes of the Northern Hemisphere are strongly weighted towards late spring, summer, and early autumn, where $\mathrm{CO}_{2}$ is known to be much lower than for the (true) yearly average. This uneven weighting is due to the significantly higher cloud cover in winter but also because of larger solar zenith angles and snow coverage. As a result, most of the measurements in winter are automatically filtered out by the implemented quality filtering scheme. To assess the quality of the measured WFM-DOAS $\mathrm{CO}_{2}$ mole fractions globally we performed a comparison with the $\mathrm{XCO}_{2}$ obtained from the global $\mathrm{CO}_{2}$ assimilation system CarbonTracker (Peters et al., 2007). The corresponding CarbonTracker $\mathrm{XCO}_{2}$ is shown in the right hand side panels of Fig. 4.

CarbonTracker has been developed by NOAA ESRL in cooperation with many partners. CarbonTracker (see also http: //www.esrl.noaa.gov/gmd/ccgg/carbontracker/) is a reanalysis of the recent global surface fluxes of carbon dioxide, as estimated from a large set of atmospheric $\mathrm{CO}_{2}$ mole fractions produced via a data assimilation system. The underlying atmospheric transport model TM5 (Krol et al., 2005) is driven by meteorological data from ECMWF. The CarbonTracker $\mathrm{XCO}_{2}$ field as used for this study has been sampled in space and time as the SCIAMACHY satellite instrument measures. The SCIAMACHY altitude sensitivity has been taken into account by applying the SCIAMACHY $\mathrm{CO}_{2}$ column averaging kernels (Buchwitz et al., 2005a) to the CarbonTracker $\mathrm{CO}_{2}$ vertical profiles (the difference between applying or not applying the SCIAMACHY averaging kernels is quite small, typically less than $1 \mathrm{ppm}$ ). Concerning the accuracy of CarbonTracker, NOAA's comparison to about 14000 independent aircraft profiles sampled mostly over North America shows agreement within one standard deviation of $\pm 1.9 \mathrm{ppm}$ over multiple years, distributed as $\pm 1.5 \mathrm{ppm}$ in winter, and $\pm 2.7 \mathrm{ppm}$ in summer; biases are within $0.5 \mathrm{ppm}$ in each season and nearly zero for the multiyear average (Wouter Peters, NOAA, personal communication; see also the CarbonTracker product evaluations website http://www. esrl.noaa.gov/gmd/ccgg/carbontracker/profiles.php showing agreeement within typically $\pm 4 \mathrm{ppm})$. For all comparisons with CarbonTracker the SCIAMACHY $\mathrm{CO}_{2}$ data have been scaled by a constant factor of 1.015 to compensate a small 

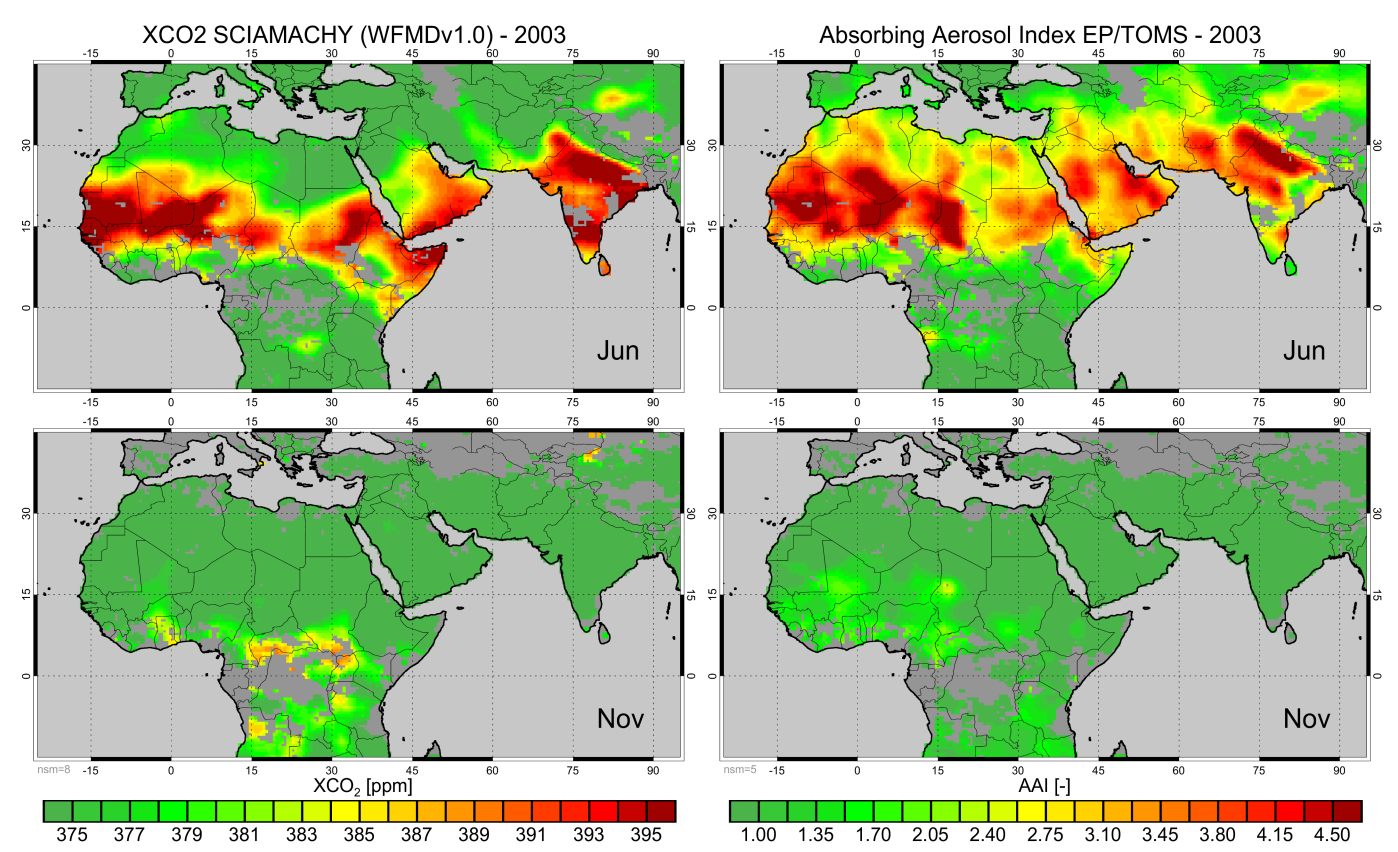

Fig. 5. The left panels shows SCIAMACHY $\mathrm{XCO}_{2}$ not filtered for aerosol contamination (top: June 2003, bottom: November 2003). The two panels on the right show the Absorbing Aerosol Index (AAI) data product from TOMS/Earth Probe. The data have been smoothed using a boxcar function.

systematic bias between the two data sets, which is, however, uncritical for application in inverse modeling as constant biases can be relatively easy corrected, especially if they are known. A similar low bias is also observed relative to Fourier Transform Spectrometers (see following subsection). There are several possible causes for a relatively small overall bias, e.g., errors of the spectroscopic data (e.g., line intensity errors) but also the assumed aerosol scenario as we use a single aerosol scenario with a relatively high aerosol optical depth (higher than a global average).

As can be seen in Fig. 4, the $\mathrm{CO}_{2}$ pattern as retrieved from SCIAMACHY are similar for all years but shifted upwards from one year to the next due to a general quite homogeneous increase of the retrieved $\mathrm{CO}_{2}$ with time. This can also be seen in the CarbonTracker $\mathrm{XCO}_{2}$. The observed $\mathrm{CO}_{2}$ increase is also demonstrated by the linear fits shown in Fig. 11 which are almost identical to CarbonTracker, and amount to about $1.0 \%$ from the beginning of 2003 to the end of 2005. In this context it is important to point out, as already explained earlier, that no a-priori information is used about increasing $\mathrm{CO}_{2}$ in the retrieval procedure. A more quantitative discussion of this is given in Buchwitz et al. (2007b). The main difference between the SCIAMACHY $\mathrm{XCO}_{2}$ and the CarbonTracker $\mathrm{XCO}_{2}$ is that the retrieved $\mathrm{XCO}_{2}$ spatial pattern are about a factor of two more variable (about $\pm 12 \mathrm{ppm}$ for SCIAMACHY compared to about $\pm 6 \mathrm{ppm}$ for CarbonTracker). The largest $\mathrm{XCO}_{2}$ values in the yearly averages as retrieved from SCIAMACHY are over the tropical regions. Although also CarbonTracker sampled as SCIAMACHY measures shows regionally elevated $\mathrm{XCO}_{2}$ over parts of the tropics, the satellite derived $\mathrm{XCO}_{2}$ is significantly higher, e.g., over central Africa and over the northern part of South America. This may partially be due to retrieval errors caused by undetected subvisual cirrus clouds (a detailed discussion of this aspect is given below) which occur frequently over this region (Liu, 2007).

\section{$5.2 \mathrm{CO}_{2}$ seasonal cycle}

To validate the retrieved $\mathrm{XCO}_{2}$ data, the SCIAMACHY WFM-DOAS version $1.0 \mathrm{XCO}_{2}$ has been compared with Fourier Transform Spectrometer (FTS) measurements performed at Park Falls, Wisconsin, USA (Washenfelder et al., 2006) (obtained from http://www.tccon.caltech.edu/) and at Bremen, Germany (Macatangay et al., 2008 ${ }^{1}$ ). Figure 10 shows the comparison between the FTS and SCIAMACHY data sets for both locations based on monthly averages. For the $\mathrm{XCO}_{2}$ data from SCIAMACHY a radius of $350 \mathrm{~km}$ around the measurement site has been selected and the monthly composite is made of $\mathrm{XCO}_{2}$ data classified as "good", which fall within this region. The data are plotted as anomalies, i.e., with SCIAMACHY and FTS mean values subtracted (on average the SCIAMACHY data are about

\footnotetext{
${ }^{1}$ Macatangay, R., Warneke, T., Gerbig, C., Körner, S., Heimann, M., and Notholt, J.: Spatial Variability of Column Averaged VMRs of $\mathrm{CO}_{2}$ over Bremen, Germany, in preparation, 2008.
} 


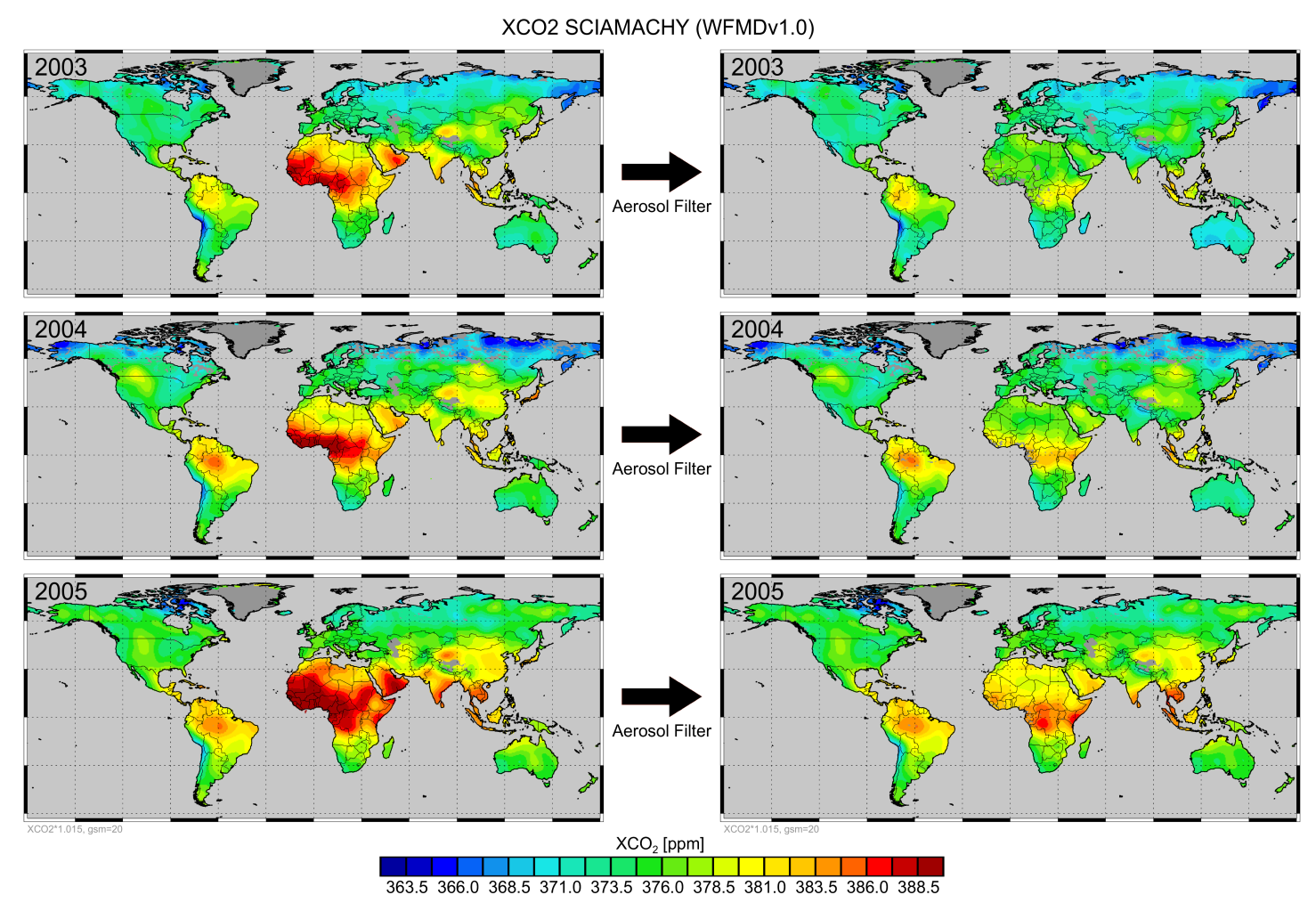

Fig. 6. Yearly averages of SCIAMACHY $\mathrm{CO}_{2}$ showing the data without (left) and with (right) aerosol (AAI) filtering. The AAI filtered SCIAMACHY data show better agreement with CarbonTracker (see Fig. 4) than the unfiltered data. Note that the panels shown on the right are identical with the left hand side panels of Fig. 4.

1-2\% lower than FTS; the exact biases are given in Fig. 10, see $\mathrm{d} \%$ ). To maximize the number of SCIAMACHY data points we used a slightly relaxed WFM-DOAS quality criterion (allowing an $\mathrm{O}_{2}$ fit residuum RMS up to 0.025 instead of the standard value of 0.02). As can be seen, despite the larger scatter of the single measurement of SCIAMACHY $\mathrm{XCO}_{2}$, which is on average about $9 \mathrm{ppm}$, good agreement is obtained for the monthly composite averages with respect to the amplitude and the phase of the seasonal cycle of $\mathrm{CO}_{2}$ over Park Falls. The correlation coefficient between the two data sets is 0.94 . For the standard quality filtering with somewhat less data points available for comparison, the correlation coefficient is 0.88 . The agreement with the FTS in Bremen is somewhat worse $(r=0.73)$ most likely because of the larger variability of the atmospheric $\mathrm{CO}_{2}$ in northern Germany, with many local sources compared to Park Falls. Assuming that the time dependence of the total peak-to-peak $\mathrm{XCO}_{2}$ measurement error from the error analysis in Sect. 4 is perfectly correlated with the $\mathrm{CO}_{2}$ seasonal cycle, which is not exactly the case, the upper bound of the error of the amplitude of the measured $\mathrm{CO}_{2}$ seasonal cycle due to the examined error sources is estimated to be $0.5 \%$ or $2 \mathrm{ppm}$ (half of the total $\mathrm{XCO}_{2}$ peak-to-peak measurement error determined in Sect. 4).
Similar results have been reported recently for a comparison of SCIAMACHY $\mathrm{CO}_{2}$ retrieved using FSI/WFM-DOAS (Barkley et al., 2007) with the Park Falls FTS data. Based on a comparison of daily data, Barkley et al. (2007) report correlation coefficients in the range $0.36-0.73$ (their Table 1) depending on spatial collocation with typically higher correlation for the more relaxed spatial collocation limits. For monthly mean data Barkley et al. (2007) also report a correlation coefficient of 0.94 as found here for WFM-DOAS. Similar remarks apply to the $1-2 \%$ low bias of the SCIAMACHY XCO $\mathrm{XCl}_{2}$ relative to the Park Falls FTS. Furthermore, also the scatter of the single ground pixel $\mathrm{XCO}_{2}$ retrievals of the two independently generated SCIAMACHY data sets is similar.

A hemispheric comparison of the WFM-DOAS version $1.0 \mathrm{XCO}_{2}$ with CarbonTracker based on daily data is shown in Fig. 11. As can be seen, the retrieved $\mathrm{XCO}_{2}$ seasonal cycle over the Northern Hemisphere shows good agreement with CarbonTracker $(r=0.86)$. The northern hemispheric amplitude of the seasonal cycle retrieved by SCIAMACHY $(6 \mathrm{ppm})$ is however somewhat larger than for CarbonTracker (4 ppm). 


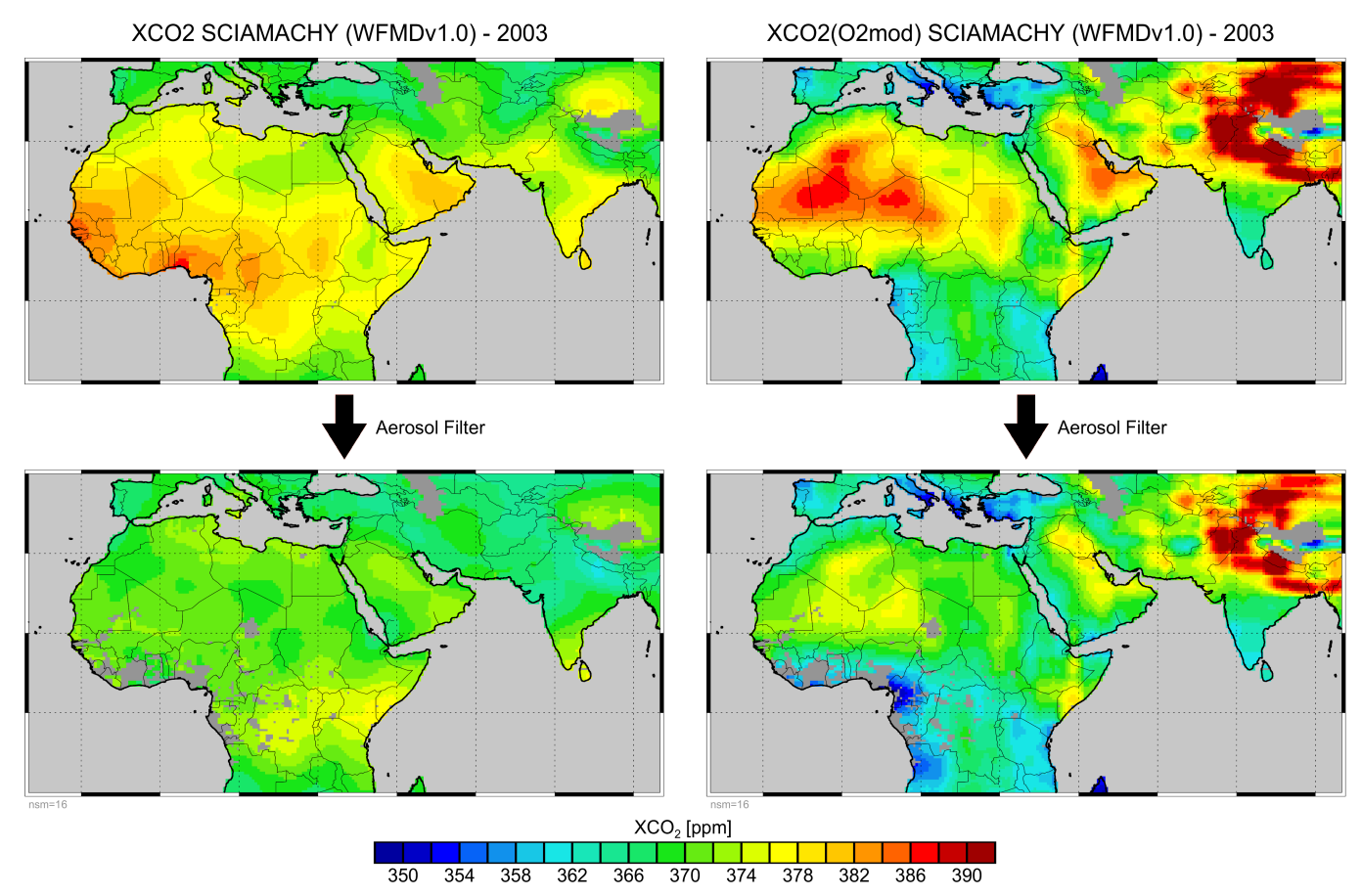

Fig. 7. Comparison between two SCIAMACHY $\mathrm{XCO}_{2}$ data products. On the left hand side the standard $\mathrm{XCO}_{2}$ data product is shown which is based on normalizing the measured $\mathrm{CO}_{2}$ column by the simultaneously measured $\mathrm{O}_{2}$ column without (top) and with (bottom) AAI (aerosol) filtering applied. On the right hand side the measured $\mathrm{CO}_{2}$ is normalized using model $\mathrm{O}_{2}$ columns obtained from CarbonTracker meteorological (ECMWF) surface pressure. The data have been smoothed using a boxcar function.

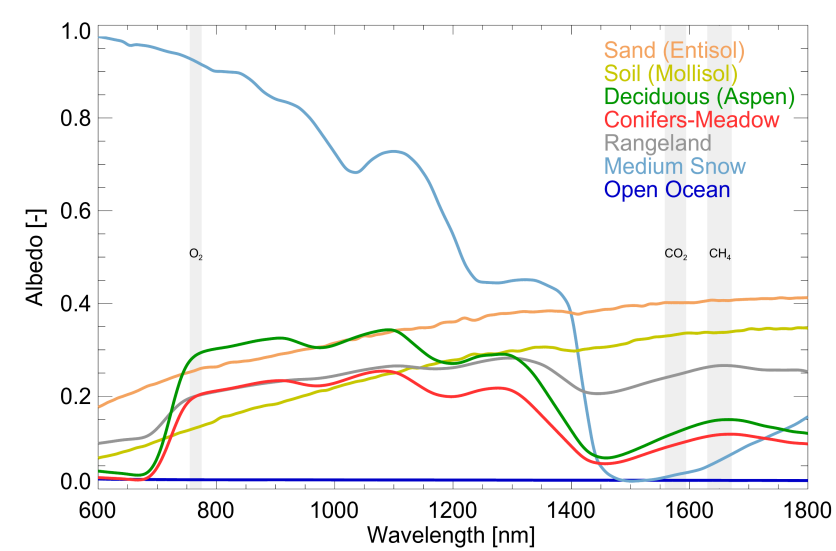

Fig. 8. Spectral albedos of different natural surface types. Reproduced from the ASTER Spectral Library through the courtesy of the Jet Propulsion Laboratory, California Institute of Technology, Pasadena, California (C1999, California Institute of Technology) and the Digital Spectral Library 06 of the US Geological Survey.

The seasonal variation, as measured by SCIAMACHY, is however significantly different for the Southern Hemisphere concerning both amplitude (4-5 ppm for SCIAMACHY compared to 1-2 ppm for CarbonTracker) as well as phase. Olsen et al. (2004) report a seasonal amplitude of $\sim 3 \mathrm{ppm}$ for southern hemispheric Africa and South America derived from independent model simulations. Figure 11 shows that the SCIAMACHY $\mathrm{XCO}_{2}$ over the Southern Hemisphere is significantly noisier (larger scatter of the daily means) compared to the Northern Hemisphere. This is because of the smaller (ice and snow free) landmass in the Southern Hemisphere, to which the SCIAMACHY data are restricted, resulting in less data available for averaging. This may contribute to the larger differences to CarbonTracker over the Southern Hemisphere compared to the Northern Hemisphere but probably cannot explain the significantly different seasonal cycles. Figure 12 shows the column amounts of SCIAMACHY carbon dioxide and oxygen in comparison to CarbonTracker (computed from surface pressure and $\mathrm{CO}_{2}$ mole fraction). The deviations from CarbonTracker of the column amounts have a very similar structure in the Northern Hemisphere and cancel to a large extent when computing the mole fraction $\mathrm{XCO}_{2}$ leading to the good agreement demonstrated in Fig. 11. In the Southern Hemisphere the small additional negative offset in both columns cancels perfectly when computing the ratio.

The main reason for the deviation of the retrieved carbon dioxide mole fractions in the southern hemisphere is most 

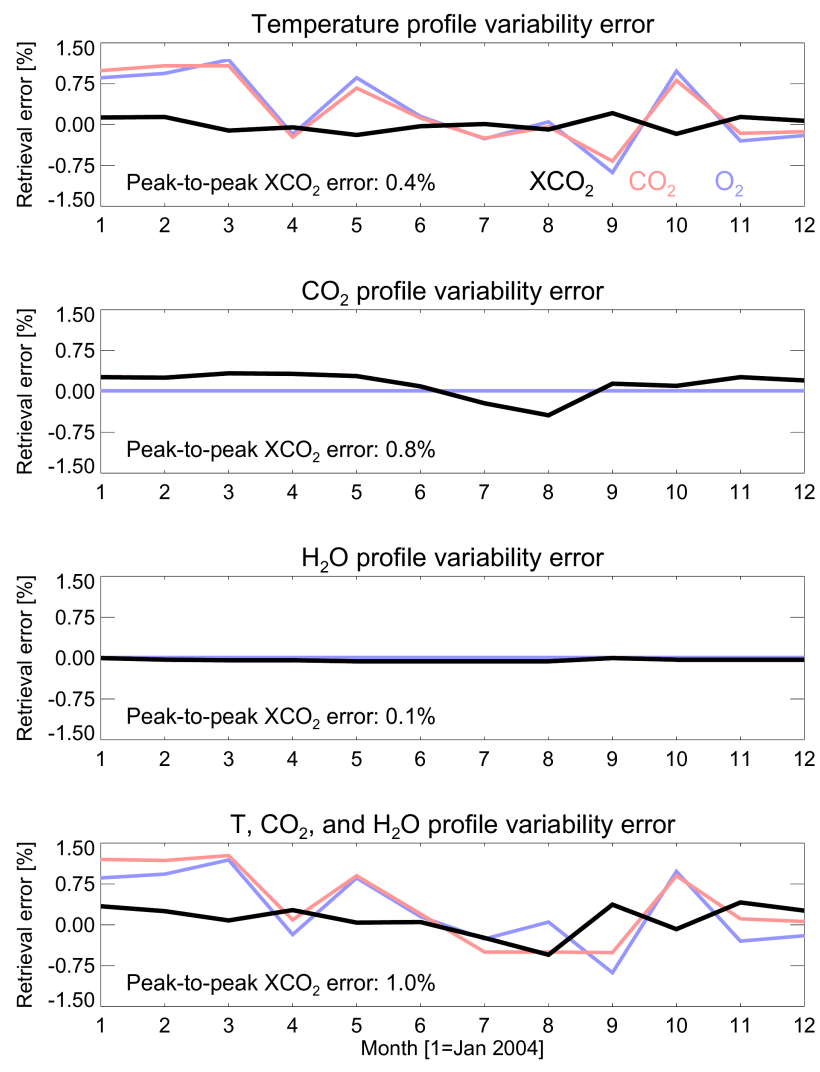

Fig. 9. Results of an error analysis of the SCIAMACHY $\mathrm{XCO}_{2}$ retrievals based on simulated retrievals focusing on the error of the $\mathrm{CO}_{2}$ seasonal cycle. For each month simulated spectra have been computed using different vertical profiles of temperature, water vapour, and $\mathrm{CO}_{2}$. The time dependent temperature and water vapour profiles are from ECMWF; the $\mathrm{CO}_{2}$ profiles are from CarbonTracker. The simulations correspond to Park Falls, Wisconsin, USA, and are assumed to be approximately representative for northern hemispheric mid-latitudes. The top panel shows the retrieval errors for the $\mathrm{CO}_{2}$ and $\mathrm{O}_{2}$ column (in red and blue, respectively) and for $\mathrm{XCO}_{2}$ (black) due to temperature profile variability. The second panel shows the error due to $\mathrm{CO}_{2}$ profile variability (for the retrieval a constant $\mathrm{CO}_{2}$ mixing ratio vertical profile is assumed). The third panel shows the error due to water vapour variability. The bottom panel shows the total error when all three error sources are combined.

probably the higher weight on ground scenes with occurrences of subvisual cirrus clouds (scattering optical depth less than about 0.03 ) which are a potential significant error source leading to a possible overestimation of the carbon dioxide mole fractions due to the $\mathrm{O}_{2}$ normalization (see Table 5). Actually, the difference of the retrieved and modeled seasonal cycle over the southern hemisphere with maximum in December/January and minimum in July/August is highly correlated $(r=0.94)$ with the strong seasonal variations of the subvisual cirrus fraction (approximately sampled as SCIA-
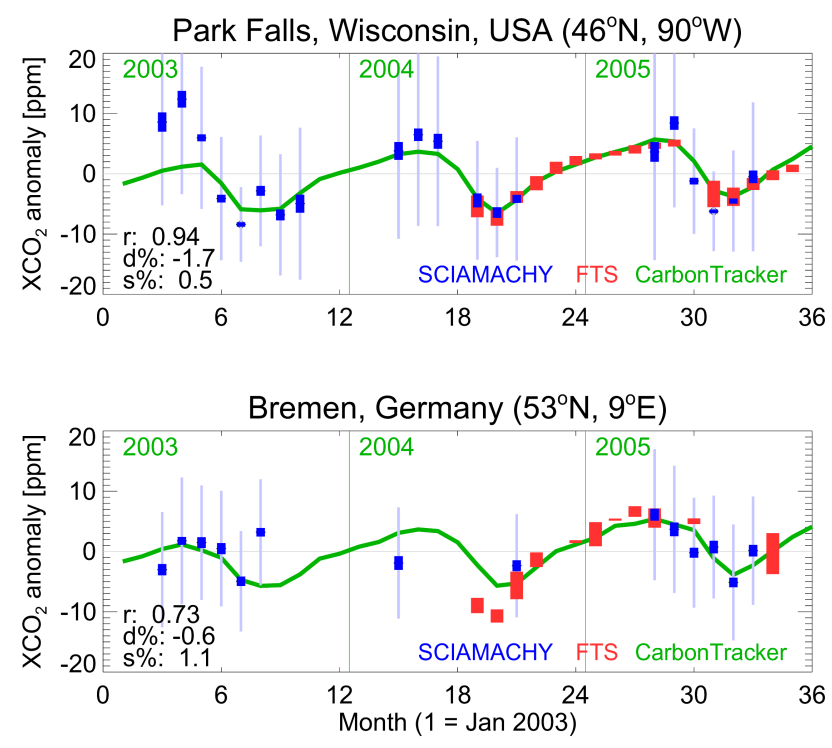

Fig. 10. Comparison of the satellite $\mathrm{XCO}_{2}$ (blue) with ground based Fourier Transform Spectroscopy (FTS) measurements (red) for Park Falls, Wisconsin, USA (top), and Bremen, northern Germany (bottom). Also included are corresponding CarbonTracker results (green). Shown are comparisons of $\mathrm{XCO}_{2}$ anomalies, i.e., the corresponding mean values have been subtracted. All qualityfiltered SCIAMACHY measurements within a radius of $350 \mathrm{~km}$ around the ground station are considered for the comparison. The thin light blue vertical bars correspond to the standard deviation of the SCIAMACHY data within a given month, i.e., correspond to the measured single ground pixel $\mathrm{XCO}_{2}$ variability. The thicker (darker) blue vertical bars are an estimate of the statistical error of the SCIAMACHY monthly mean $\mathrm{XCO}_{2}$. The red bars show the standard deviation of the FTS data. The following numbers have been computed based on the monthly averages: $d \%$ is the mean difference SCIAMACHY-FTS in percent, $s \%$ denotes the standard deviation of the difference in percent, and $r$ is the correlation coefficient. Note that these numbers are valid for the absolute $\mathrm{XCO}_{2}$, i.e., not for the anomalies, and for SCIAMACHY $\mathrm{XCO}_{2}$ which has not been scaled by 1.015 (therefore $d \%$ quantifies the systematic bias of the SCIAMACHY $\mathrm{XCO}_{2}$ relative to the FTS).

MACHY measures) as concluded using preliminary subvisual cirrus retrievals (provided by E. Martins, LMD/IPSL, France; Martins et al., Subvisual cirrus clouds at global scale from CALIPSO lidar observations, poster presented at EGU 2008, Vienna, Austria) based on Level 1 v2.01 CALIPSO data. Our analysis is based on the assumption that the broad scale features (e.g., monthly hemispheric averages) of the subvisual cirrus occurrences are representative also for other years as the CALIPSO data set is covering a different time period (June 2006-March 2008).

Another possible contribution to the deviation of the resulting SCIAMACHY $\mathrm{XCO}_{2}$ seasonal variations from CarbonTracker in the Southern Hemisphere could be a SZA (or airmass) dependent error resulting for example from 

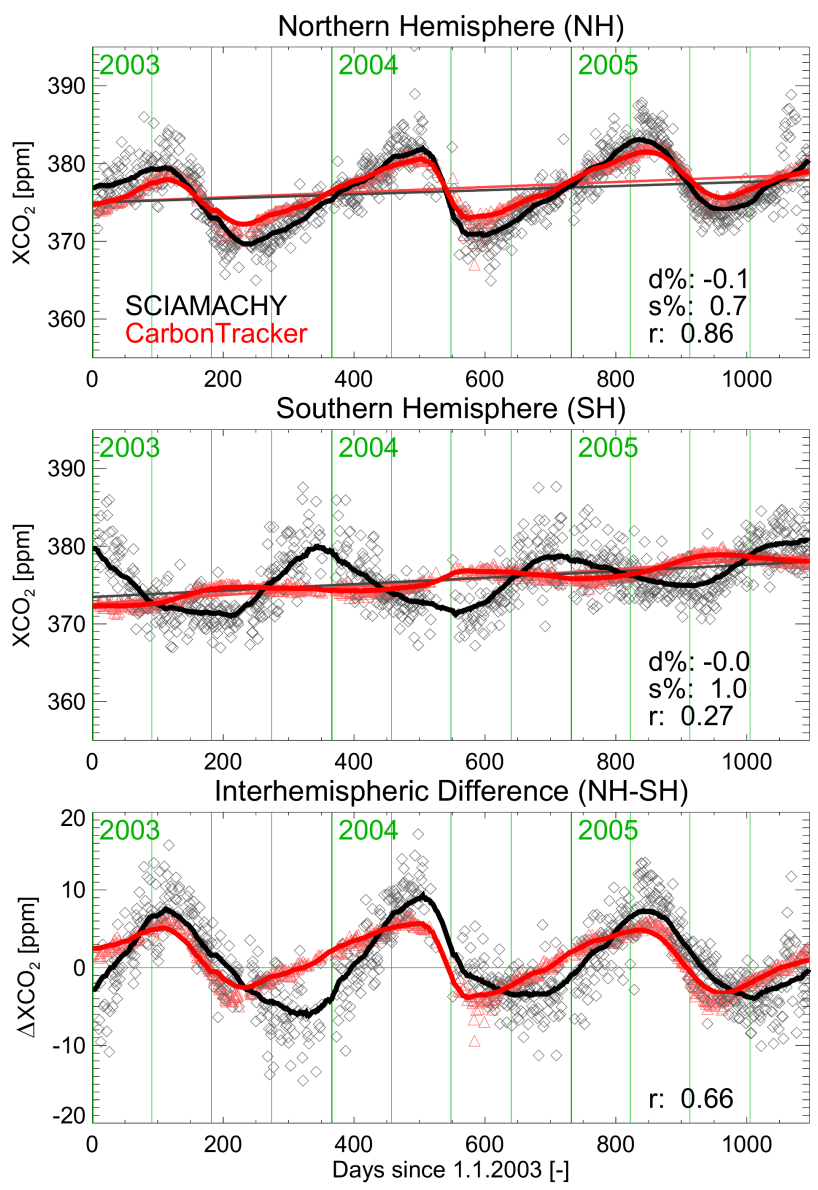

Fig. 11. Comparison of the SCIAMACHY (black) and CarbonTracker (red) $\mathrm{XCO}_{2}$ for the Northern Hemisphere (top left), the Southern Hemisphere (top right) and for the interhemispheric $\mathrm{XCO}_{2}$ difference (bottom). For the comparison both the daily SCIAMACHY and CarbonTracker data have been gridded on a common $0.5^{\circ} \times 0.5^{\circ}$ latitude/longitude grid. The symbols show the daily average of all coincident grid cells in the corresponding hemisphere. For SCIAMACHY all measurements passing the aerosol filter have been averaged for which the WFMDv 1.0 quality flag indicates a "good" measurement. The solid lines represent a 90 days running average and the straight lines the corresponding linear fits further demonstrating the increase of $\mathrm{XCO}_{2}$ with time. For each hemisphere the following numbers have been computed based on the (not smoothed) daily averages: $d \%$ is the mean difference SCIAMACHY-CarbonTracker in percent, $s \%$ denotes the standard deviation of the difference in percent, and $r$ is the correlation coefficient. Note that the SCIAMACHY $\mathrm{XCO}_{2}$ has been scaled with 1.015 to compensate for an approximately $1.5 \%$ low bias relative to CarbonTracker (as demonstrated by $d \%$ which is essentially zero).

neglecting polarization in the radiative transfer (Natraj et al., 2006) or from errors in the spectroscopic data, e.g., errors of the air-broadened half width of the $\mathrm{CO}_{2}$ and/or $\mathrm{O}_{2}$ absorption lines, as discussed in Washenfelder et al. (2006) for the
Park Falls $\mathrm{XCO}_{2}$ FTS measurements. Such kind of errors can contribute to the differences shown in Fig. 11 but probably cannot fully explain the difference to CarbonTracker over the Southern Hemisphere because of the much better agreement with CarbonTracker over the Northern Hemisphere. If a SZA dependent error for example due to errors in the spectroscopic data would be the only reason for the difference of the SCIAMACHY and CarbonTracker seasonal cycles, then the difference should be similar for both hemispheres except for a six months phase shift. This however is not the case.

Nevertheless, spectroscopic errors may contribute to the differences shown in Fig. 11 and we estimated the sensitivity of the retrieved $\mathrm{XCO}_{2}$ to changes in the $\mathrm{CO}_{2}$ and $\mathrm{O}_{2}$ absorption line width. Why can line width errors result in a SZA dependent $\mathrm{CO}_{2}$ or $\mathrm{O}_{2}$ column retrieval error? This can be explained by increasing "saturation" of the depth of non-resolved strong absorption lines with increasing absorber amount along the light path (Goody and Yung, 1989), an effect which is also nicely illustrated in Frankenberg et al. (2005) for SCIAMACHY methane measurements (see their Figs. 1 and 2). Here saturation refers to the decrease of the sensitivity of the (logarithm of the) measured spectrum to changes in the absorber amount along the light path, for example due to an increasing SZA. As a wider line shows less saturation (in the line center) compared to a narrower line (assuming identical line intensities and line shape functions), and because the SZA dependence of the saturation will be different for the two lines, a line width error may result in a SZA dependent retrieval error. Therefore one typically would expect an underestimation (overestimation) of the retrieved column which increases with increasing SZA, if the line width is in reality narrower (wider) than assumed for the retrieval (a narrower monochromatic line is deeper compared to an equivalent wider line, but if the lines are strong and not resolved, the opposite is true). To quantify this error we performed retrievals based on simulated spectra for a range of solar zenith angles for different assumed airbroadened line width errors (assuming that the width of all lines change identically by a certain percentage). The values we report here are for the two extreme solar zenith angles, namely $15^{\circ}$ (which is approximately the lowest SZA encountered by SCIAMACHY) and $75^{\circ}$ (the upper limit accepted for this study). We found that if all $\mathrm{CO}_{2}$ lines would (in reality) be narrower by $1 \%$ compared to the air-broadened line widths currently assumed for retrieval (HITRAN 2004, Rothman et al., 2005), this would result in retrieved $\mathrm{CO}_{2}$ column being underestimated by $\sim 0.4 \%$ for a SZA of $15^{\circ}$ and by $\sim 0.5 \%$ for a SZA of $75^{\circ}$, i.e., the underestimation increases with increasing SZA, in agreement with the discussion given above, by $0.1 \%$ for $\mathrm{CO}_{2}$. For $\mathrm{O}_{2}$ we found a larger offset, but a negligible SZA dependence compared to $\mathrm{CO}_{2}$. This means that the SZA dependent part of the $\mathrm{XCO}_{2}$ error appears to be dominated by the SZA dependent part of the $\mathrm{CO}_{2}$ column error, i.e., $0.1 \%$ if the line widths would be off by $1 \%$. We repeated this investigation for a range of line width errors and 

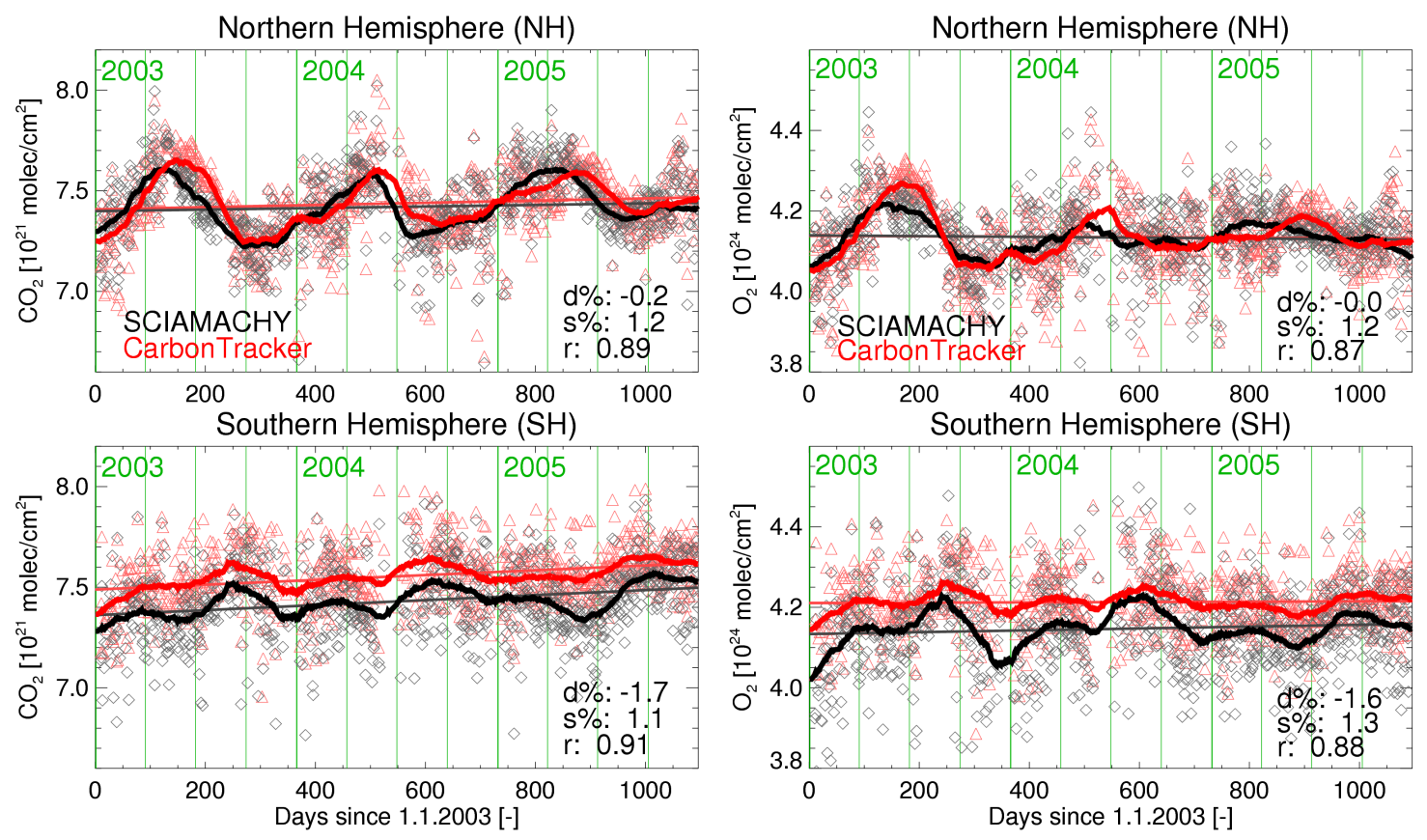

Fig. 12. As Fig. 11 but for the column amounts of carbon dioxide (left) and oxygen (right). The SCIAMACHY CO $\mathrm{C}_{2}$ has been scaled with 1.015. The deviations of the $\mathrm{CO}_{2}$ and $\mathrm{O}_{2}$ columns from CarbonTracker have a very similar structure in the Northern Hemisphere (top) and cancel to a large extent when computing the mole fraction $\mathrm{XCO}_{2}$ leading to the good agreement between SCIAMACHY and CarbonTracker demonstrated in the previous figure. In the Southern Hemisphere (bottom) the small additional negative offset in both columns cancels nearly perfectly when computing the ratio.

SZAs and found that the SZA dependent part of the $\mathrm{XCO}_{2}$ error depends to a good approximation linearly on the assumed line width error resulting in an approximately $0.5 \mathrm{ppm} \mathrm{XCO}_{2}$ error (peak-to-peak) per 1\% line width error (the results for Lauder, New Zealand, are shown in Fig. 13). This means that the differences to CarbonTracker over the Southern Hemisphere of about $6 \mathrm{ppm}$ peak-to-peak would correspond to an air-broadened line width error of $12 \%$ which is higher, but not very much higher, than the uncertainty of the spectroscopic data which are $5-10 \%$ for $\mathrm{CO}_{2}\left(2-5 \%\right.$ for $\left.\mathrm{O}_{2}\right)$. Finally we would like to point out that the retrieved $\mathrm{XCO}_{2}$ over the Southern Hemisphere (or, more precisely, the difference to CarbonTracker) is (anti-)correlated with the SZA, which has a maximum in winter, i.e., in the middle of the year. This is not true, however, for the Northern Hemisphere, as the difference to CarbonTracker is not symmetric with respect to the middle of the year. From this one can conclude that a SZA dependent error, for example due to spectroscopic errors, may contribute significantly to the differences between the SCIAMACHY and CarbonTracker $\mathrm{XCO}_{2}$ shown in Fig. 11 but cannot explain all the differences.

Figure 14 shows global bi-monthly maps of the $\mathrm{XCO}_{2}$ spatial pattern observed when sampling the seasonal cycle during its (northern hemispheric) $\mathrm{XCO}_{2}$ maximum and minimum time periods. Significant seasonal variability is visible

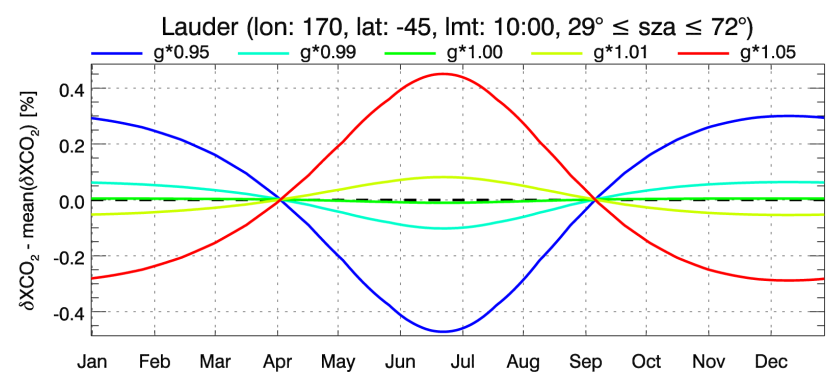

Fig. 13. Sensitivity of the retrieved SCIAMACHY $\mathrm{XCO}_{2}$ with respect to the $\mathrm{CO}_{2}$ air-broadened line width for Lauder, New Zealand. Each curve corresponds to a different assumed error of the airbroadened line width. The blue curve, for example, corresponds to a line width error of $5 \%(\mathrm{~g} * 0.95$ means that a true line width is assumed which is 0.95 times the line width assumed for the $\mathrm{XCO}_{2}$ retrieval). All errors are shown as percentage errors (negative values correspond to an underestimation of the retrieved $\mathrm{XCO}_{2}$ ) and as anomalies, i.e., the mean value of each curve has been subtracted to highlight the time (SZA) dependence of the potential retrieval error.

in both the SCIAMACHY and the CarbonTracker data. This variability of the $\mathrm{CO}_{2}$ spatial pattern is dominated by the seasonal uptake and release of $\mathrm{CO}_{2}$ by the Northern Hemisphere 

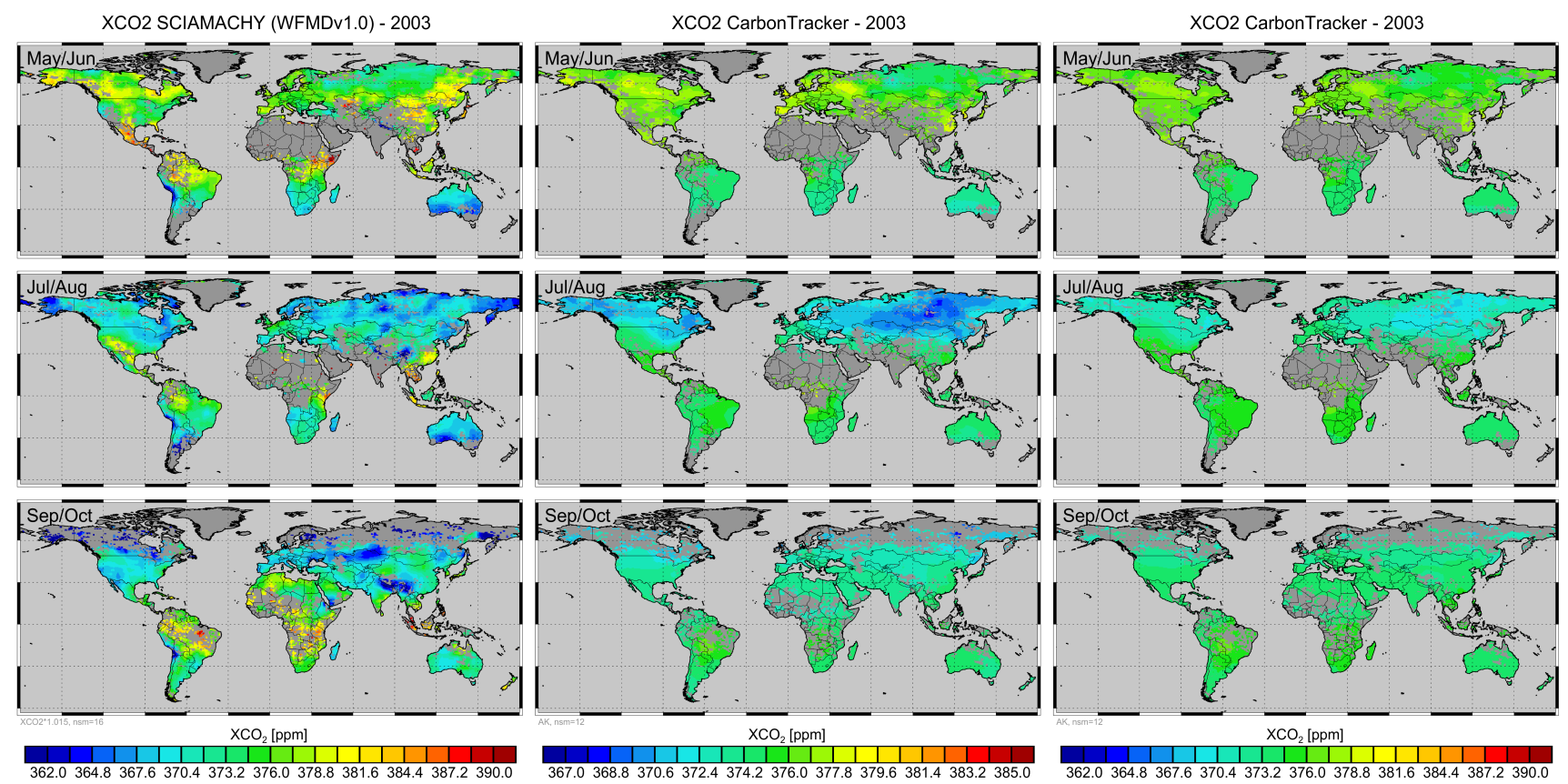

Fig. 14. Bi-monthly averages of the SCIAMACHY $\mathrm{XCO}_{2}$ (left) compared to CarbonTracker using an appropriate color scale (middle) as well as the same color scale as has been used for the satellite data (right). Shown are only those measurements for which the WFM-DOAS quality flag indicates a good measurement (see main text for details). The SCIAMACHY $\mathrm{XCO}_{2}$ has been aerosol filtered and plotted after smoothing with a boxcar function.

terrestrial biosphere, resulting in much lower $\mathrm{XCO}_{2}$ during July/August compared to, e.g., May/June in the northern hemispheric mid and high latitudes covered by, e.g., the boreal forests. Figure 14 shows that both data sets, SCIAMACHY and CarbonTracker $\mathrm{XCO}_{2}$, are clearly correlated. The SCIAMACHY data show however significantly larger variability; for this reason two different color scales have been used for Fig. 14 ( \pm 14 ppm for SCIAMACHY compared to $\pm 9 \mathrm{ppm}$ for CarbonTracker).

\section{$5.3 \quad \mathrm{CO}_{2}$ regional pattern}

To enable a more detailed comparison on the regional scale, Figs. 15 and 16 show monthly composite averages of the satellite data and CarbonTracker over large parts of the Northern Hemisphere, namely USA, Canada and Eurasia. The horizontal resolution of the maps shown in Figs. 15-16 is $7^{\circ} \times 7^{\circ}$. The data are shown as anomalies, i.e., the mean value has been subtracted for each map, to enable a better comparison of the spatial pattern. As can be seen, the two independent $\mathrm{XCO}_{2}$ data sets are clearly correlated in space and time indicating that the satellite data capture spatio-temporal atmospheric $\mathrm{CO}_{2}$ variability on a regional scale. Many of the larger scale features which show up in the CarbonTracker $\mathrm{XCO}_{2}$ are also visible in the satellite data, for example the extended region of low $\mathrm{XCO}_{2}$ over eastern Canada in $\mathrm{Au}-$ gust 2005 and the relatively high $\mathrm{XCO}_{2}$ over the southern USA in particular in July and August. There are however also significant differences. The differences with respect to CarbonTracker shown in Figs. 15 and 16 cannot be explained by a possible SZA dependent retrieval error discussed in the previous section, as the variation of the SZA is small for the maps shown in Figs. 15 and 16 (especially in the east to west direction where the SZA is essentially constant) and because only $\mathrm{XCO}_{2}$ anomalies are shown, i.e., the $\mathrm{XCO}_{2}$ mean value (which could be affected by a SZA dependent error) has been subtracted for each map. Typically the retrieved variability in the SCIAMACHY data product is about $4 \mathrm{ppm}$ ( $\sim 1 \%$ of $380 \mathrm{ppm}$ ) higher compared to CarbonTracker. But depending on time and location the differences can exceed $8 \mathrm{ppm}$. Similar conclusions can be drawn for other time periods (2003 and 2004) and other regions (e.g., South America), not shown here. A clear interpretation of the differences to CarbonTracker cannot be offered at present. As discussed in Sect. 5 the estimated accuracy of CarbonTracker is about a few ppm. In the error analysis of the WFM-DOAS retrieval algorithm presented in Sect. 4 we have identified several error sources which may contribute to the overall error of a single measurement. Most of the individual errors are typically less than $1 \%$ for a single measurement but the results shown in Figs. 15-16 are averages over many individual measurements. The random error (precision) is probably very small, 
USA \& Canada (mid-west/east)

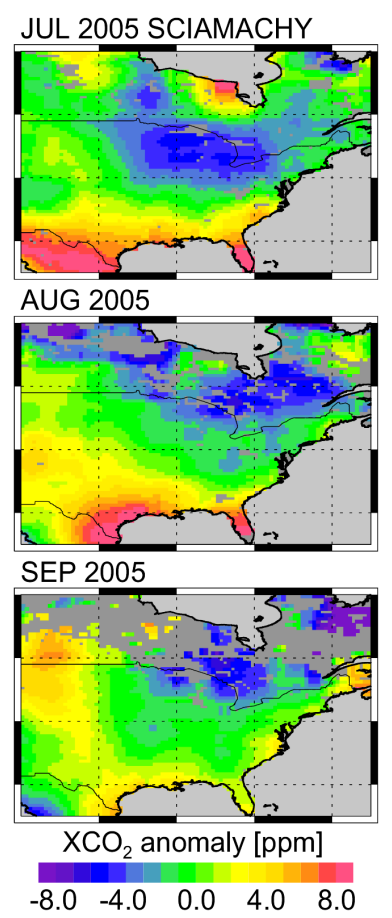

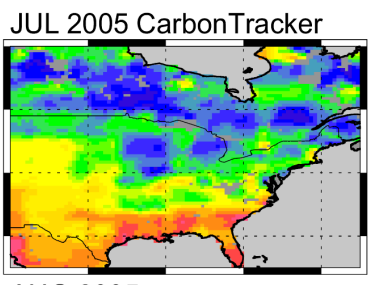
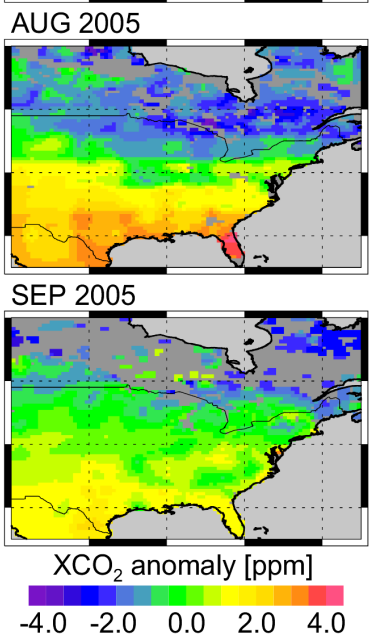

Lat: 25 to 60 , Lon: -110 to -65

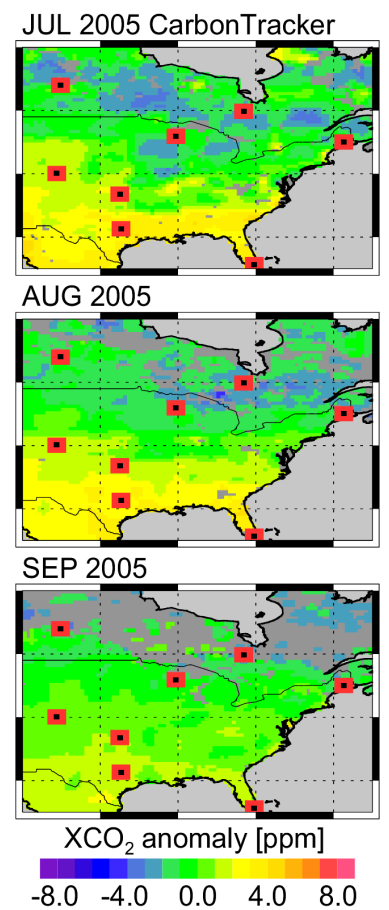

Fig. 15. The spatial pattern of $\mathrm{XCO}_{2}$ over parts of the United States of America and Canada. The $\mathrm{XCO}_{2}$ field is shown here as anomaly, i.e., the $\mathrm{XCO}_{2}$ mean value has been subtracted for each panel. The first column shows the $\mathrm{XCO}_{2}$ as retrieved from SCIAMACHY. The second column shows the CarbonTracker $\mathrm{XCO}_{2}$ using an appropriate (different) color scale. The last column also shows the CarbonTracker $\mathrm{XCO}_{2}$ but using the same color scale as has been used for the satellite data. The red rectangles indicate the spatial positions of observation sites used in CarbonTracker. The rows correspond to different months of the year 2005 . The spatial resolution is $7^{\circ} \times 7^{\circ}$ achieved by boxcar smoothing the $0.5^{\circ} \times 0.5^{\circ}$ gridded data. The root mean square (RMS) differences between SCIAMACHY and CarbonTracker for the region shown are: July: 2.3 ppm (0.6\%), August: $2.2 \mathrm{ppm}(0.6 \%)$, and September: $2.9 \mathrm{ppm}(0.8 \%)$.

much smaller than $1 \%$, but it is difficult to reliably estimate the systematic error which remains after averaging many individual measurements; the overall systematic error can be smaller but also larger than $1 \%$. One can however assume that the errors of the CarbonTracker and the satellite $\mathrm{XCO}_{2}$ are uncorrelated. In this case the 1-3 percent systematic differences between the satellite and the CarbonTracker $\mathrm{XCO}_{2}$ anomalies may be interpreted as an estimate of the relative accuracy of the satellite $\mathrm{XCO}_{2}$. This difference however also includes modelling errors. Based on this one may conclude that the relative accuracy of the satellite $\mathrm{XCO}_{2}$ is about 1$2 \%$.

In order to determine if regionally elevated $\mathrm{CO}_{2}$ originating from anthropogenic $\mathrm{CO}_{2}$ emissions can be detected, we averaged all the SCIAMACHY $\mathrm{XCO}_{2}$ retrievals for the years 2003-2005. Figure 17 shows the resulting map (gridded $0.5^{\circ} \times 0.5^{\circ}$ ) for Germany and surrounding countries. As can be seen, the SCIAMACHY $\mathrm{XCO}_{2}$ correlates reasonably well with population density (CIESIN/CIAT, 2005) and EDGAR anthropogenic $\mathrm{CO}_{2}$ emissions (EDGAR 3.2 Fast Track 2000 dataset (32FT2000), Olivier et al., 2005). All three data sets show an extended region of significantly elevated values covering the region central western Germany and parts of the Netherlands and Belgium, in the following referred to as the "Rhine-Main area". Similarly, enhanced $\mathrm{CO}_{2}$ is also visible over other anthropogenic source regions such as the East Coast of the United States and parts of Japan (e.g., around Tokyo) when three years of data are averaged (not shown here). Drawing on the example of Central Europe, Fig. 17 shows that the retrieved $\mathrm{XCO}_{2}$ regional enhancement over the Rhine-Main area is on average $2.7 \mathrm{ppm}(0.7 \%)$ as concluded by comparing the mean values in the two rectangular regions approximately representing the Rhine-Main area (red) and a reference background area (green) shown in Fig. 17 (top panel).

In this context it has to be pointed out that there is of course not a simple one to one relationship between the retrieved $\mathrm{XCO}_{2}$ enhancement and anthropogenic emissions because the signal is a mixture of the latter, (residual) biogenic features (mainly due to the imperfect sampling) and possible 


\section{Europe, Asia \& north-east Africa}

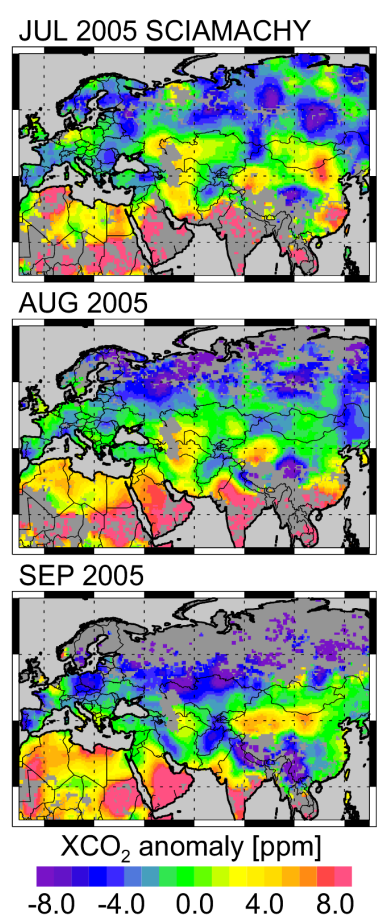

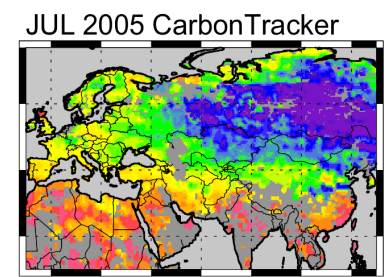
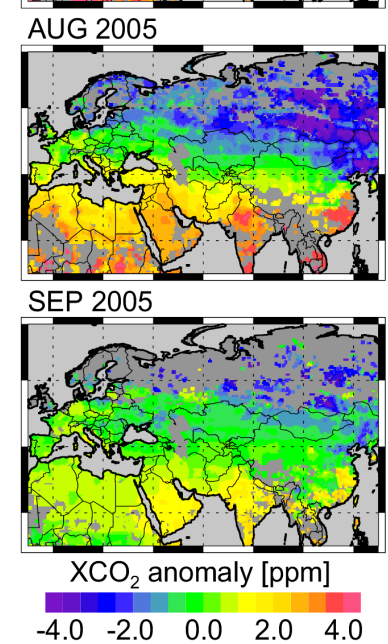

Lat: 10 to 77 , Lon: -10 to 130
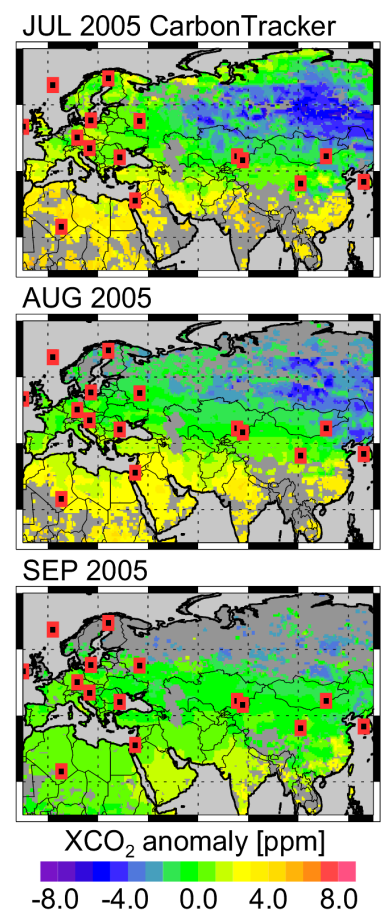

Fig. 16. As Fig. 15 but for Europe, Asia and parts of northern Africa. The RMS differences between SCIAMACHY and CarbonTracker for the region shown are: July: $4.3 \mathrm{ppm}$ (1.2\%), August: $4.0 \mathrm{ppm}$ (1.1\%), September: $5.0 \mathrm{ppm}(1.3 \%)$.

retrieval errors. What is the expected anthropogenic $\mathrm{XCO}_{2}$ signal? In Palmer et al. (2008) maps of the contribution of North American anthropogenic $\mathrm{CO}_{2}$ emissions to monthly mean $\mathrm{CO}_{2}$ column-averaged mixing ratios over the US are shown derived using the GEOS-Chem model (their Fig. 7, left hand side panels) for April-September 2003. The model has been sampled as SCIAMACHY (using a filtering of the SCIAMACHY retrievals as implemented in the FSI-WFMDOAS algorithm which is (although similar) independent of the algorithm and results shown here). In that paper it is shown that especially over the highly populated areas along the US East Coast the anthropogenic $\mathrm{XCO}_{2}$ enhancement often exceeds $1 \mathrm{ppm}$ and often reaches $2 \mathrm{ppm}$ at the model resolution of $2.0^{\circ} \times 2.5^{\circ}$. Although the EDGAR $\mathrm{CO}_{2}$ emissions along the US East Coast are comparable with the emissions in the Rhine-Main area (typically the emissions are in the range $30-70 \mathrm{Tg} /$ year per $1^{\circ} \times 1^{\circ}$ gridcell over the highly populated areas) the two regions may not be exactly comparable. For Europe, Houweling (2008) has used CarbonTracker at $1^{\circ} \times 1^{\circ}$ resolution and concludes that $1 \mathrm{ppm}$ over the RhineMain area is the maximum enhancement to be expected. Both estimates based on model simulations at relatively high spatial resolution are lower than the $2.7 \mathrm{ppm}$ enhancement shown in Fig. 17. The $\mathrm{CO}_{2}$ seasonal cycle in combination with inhomogeneous sampling as well as path length issues caused by, e.g., aerosol variability, might contribute to the observed pattern. Because of the mismatch of the resolutions, correlations between SCIAMACHY $\left(0.5^{\circ} \times 0.5^{\circ}\right)$ and CarbonTracker ( $4^{\circ}$ latitude $\times 6^{\circ}$ longitude) regarding subgrid $\mathrm{XCO}_{2}$ features can be used to identify the contribution of sampling in connection with seasonal variations and the $\mathrm{CO}_{2}$ increase with time. Assuming that CarbonTracker captures the seasonal cycle well and does not resolve the features under consideration the biogenic (seasonal cycle) influence can be minimised by analysing the daily ratio SCIAMACHY/CarbonTracker. Another independent approach to this end is the averaging of daily anomalies (obtained by subtracting the mean value of the SCIAMACHY $\mathrm{XCO}_{2}$ from all the daily observations over the region of interest before averaging). The corresponding comparison for Central Europe is illustrated in the upper panels of Fig. 18. As can be seen, the pattern of enhanced values over the Rhine-Main region is still clearly visible in both data sets indicating that this particular feature is more than coincidence. A quantitative analysis based on the two regions of Fig. 17 reveals that the regional enhancement is nearly unchanged if the seasonal variations are filtered out indicating that the contribution of inhomogeneous sampling to the observed pattern over the RhineMain area is small. By contrast the elevated $\mathrm{CO}_{2}$ retrieved over northern Germany and southern Denmark which is not 
well correlated with population density and the EDGAR $\mathrm{CO}_{2}$ emissions actually disappears or is less pronounced in the mean daily anomaly and SCIAMACHY/CarbonTracker ratio, respectively, indicating that this retrieved $\mathrm{CO}_{2}$ enhancement is probably an effect of inhomogeneous sampling.

The analysis of the contribution of path length induced errors to the observed pattern, e.g., caused by residual aerosol over urban areas missed by the quality filtering, is much more difficult as the impact of aerosol depends on the amount, height, shape, and size distribution of the particles, which are unknown. If one assumes OPAC background aerosol (aerosol optical depth of 0.19 at $550 \mathrm{~nm}$ ) with the exception of OPAC urban aerosol (additional pollution in the boundary layer and the free troposphere leading to an aerosol optical depth of 0.38 at $550 \mathrm{~nm}$ ) over the urbanized and industrialized areas under consideration (both scenarios are described in Sect. 4) one would expect an overestimation of $0.11 \%$ (about $0.5 \mathrm{ppm}$ ) taking the realistic albedos in the different fitting windows in this region into account (see Table 7). Although the choice of these aerosol scenarios seems reasonable one may argue that the real error is larger because the above estimate is derived from simulated measurements assuming certain aerosol characteristics. To estimate the contribution of aerosols from real SCIAMACHY data we analyse $\mathrm{XCH}_{4}$ normalised by $\mathrm{O}_{2}$ because, in principle, path length related errors should affect $\mathrm{XCO}_{2}$ and $\mathrm{XCH}_{4}\left(\mathrm{O}_{2}\right)$ similarly due to the $\mathrm{O}_{2}$ normalization and the neighbouring fitting windows of $\mathrm{CO}_{2}$ and $\mathrm{CH}_{4}$ which is also confirmed by the error analysis and the estimated theoretical aerosol induced overestimation discussed above (see also Table 7). Thus, path length errors might be identified via correlations between $\mathrm{XCH}_{4}\left(\mathrm{O}_{2}\right)$ and $\mathrm{XCO}_{2}$. However, this is only approximately true as methane has its own variability. The bottom left panel of Fig. 18 shows that there is no obvious one to one correlation of $\mathrm{XCH}_{4}\left(\mathrm{O}_{2}\right)$ with the retrieved enhanced $\mathrm{XCO}_{2}$ pattern discussed above (although part of the elevated $\mathrm{CO}_{2}$ over the Rhine-Main area may be due to aerosol in particular over the region south of Cologne and parts of northern Belgium where $\mathrm{XCH}_{4}\left(\mathrm{O}_{2}\right)$ is also enhanced). Similar conclusions can be drawn from the comparison with MODIS/Terra aerosol optical depth at $550 \mathrm{~nm}$ also shown in Fig. 18. This gives evidence that aerosol related errors may contribute to the elevated $\mathrm{CO}_{2}$ retrieved over the Rhine-Main area but cannot entirely explain the retrieved $\mathrm{CO}_{2}$ pattern over this anthropogeneous source region. This alternative $\mathrm{XCH}_{4}\left(\mathrm{O}_{2}\right)$ approach using the two regions (Rhine-Main and background) from Fig. 17 provides that on average only a fraction of about $0.9 \mathrm{ppm}$ of the observed $\mathrm{XCO}_{2}$ enhancement can be attributed to path length errors.

Overall we conclude from the combined analysis of real SCIAMACHY data and simulated retrievals that the elevated $\mathrm{CO}_{2}$ over the Rhine-Main region has an estimated uncertainty of about 1-1.5 ppm due to aerosols and sampling contributions. The remaining signal of about $1.2-1.7 \mathrm{ppm}$ is assumed to be mainly due to anthropogenic emissions. This
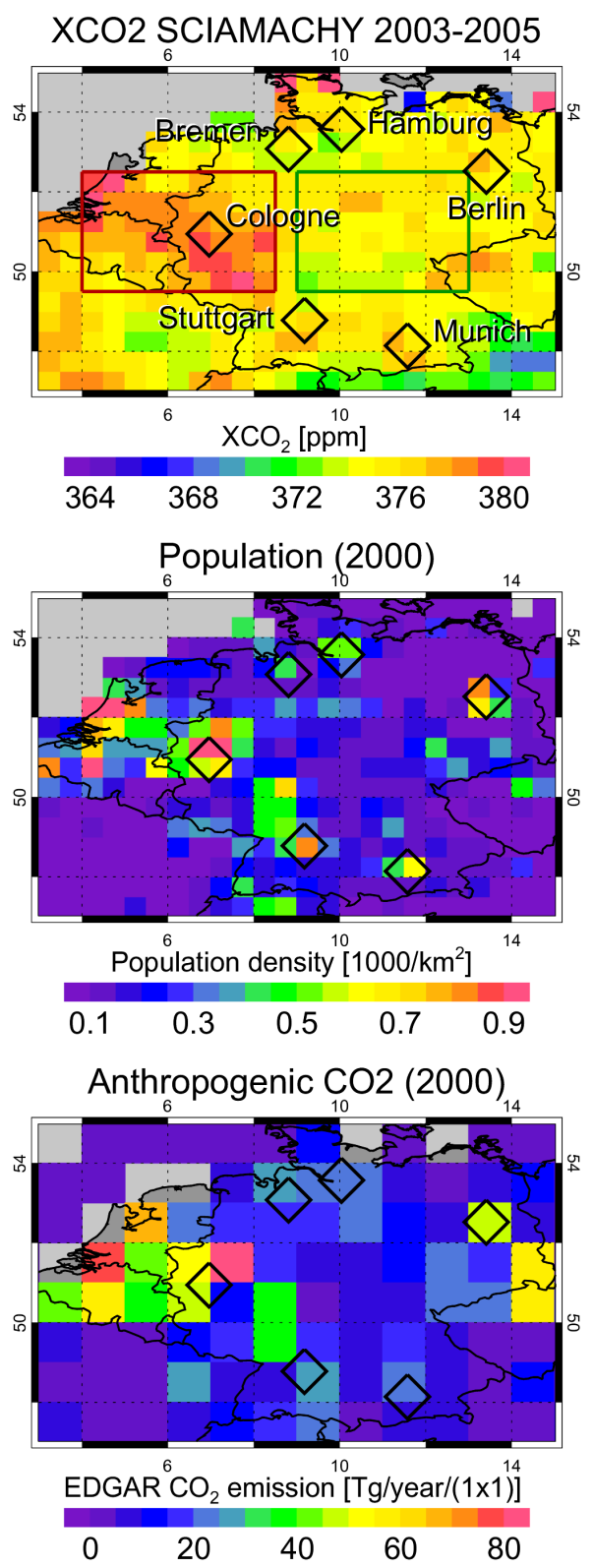

Fig. 17. SCIAMACHY $\mathrm{XCO}_{2}$ over Germany (top, $0.5^{\circ} \times 0.5^{\circ}$ gridded, scaled with 1.015) during 2003-2005 compared to population density (middle) (CIESIN/CIAT, 2005), and anthropogenic $\mathrm{CO}_{2}$ emissions (bottom, EDGAR $\left.32 \mathrm{ft} 2000,1^{\circ} \times 1^{\circ}\right)($ Olivier et al., 2005). Also shown are the regions used to quantify the regional $\mathrm{CO}_{2}$ enhancement (red and green rectangle). Note that values outside the range given by the color bar are colored with the color corresponding to the minimum or maximum value. For example, in the bottom panel one value exceeds the color bar range (the corresponding value is $137 \mathrm{Tg} /$ year/( $1 \mathrm{x} 1))$.

indicates that elevated $\mathrm{CO}_{2}$ originating from regional anthropogenic $\mathrm{CO}_{2}$ emissions can potentially be detected using measurements from space. The expected signal (order 

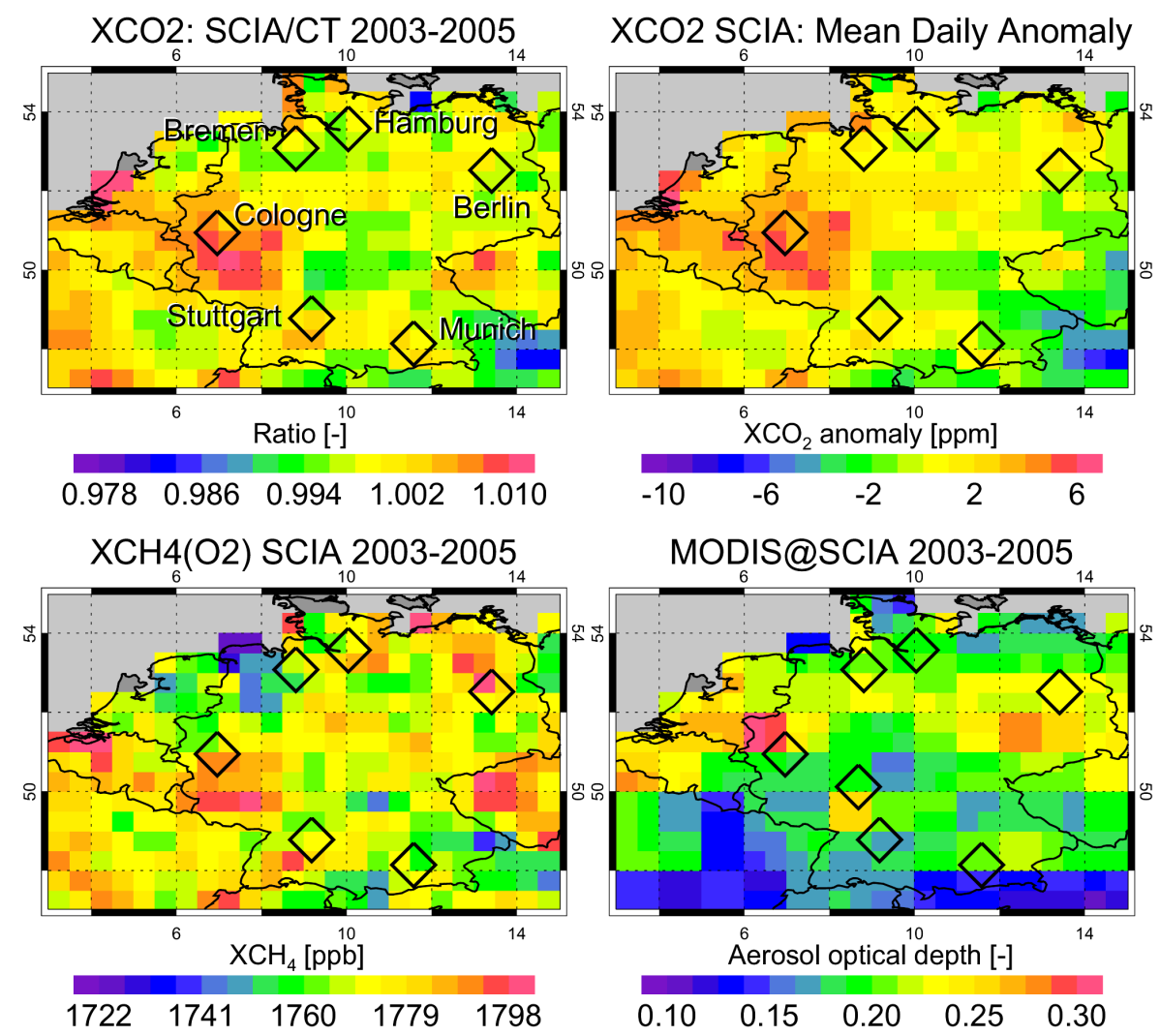

Fig. 18. Illustration of the examined contributions of inhomogeneous sampling in combination with seasonal $\mathrm{CO}_{2}$ variations (top, ratio SCIAMACHY/CarbonTracker and mean daily SCIAMACHY anomaly) and path length errors (bottom, SCIAMACHY methane normalized by $\mathrm{O}_{2}$ and MODIS/Terra aerosol optical depth at $550 \mathrm{~nm}$ approximately sampled as SCIAMACHY measures).

Table 7. Estimated overestimation due to aerosols (relative systematic error urban area versus surroundings) valid for the retrieved spectral albedo of the German Ruhrgebiet (approximately the German part of the Rhine-Main area as defined for this study), a solar zenith angle of $50^{\circ}$, and a surface elevation corresponding to sea level. As can be seen $\mathrm{XCH}_{4}\left(\mathrm{O}_{2}\right)$ and $\mathrm{XCO}_{2}$ are affected similarly.

\begin{tabular}{lrrrrr}
\hline $\begin{array}{l}\text { Aerosol scenario } \\
\text { (Ruhrgebiet) }\end{array}$ & $\begin{array}{r}\mathrm{CH}_{4} \text { column } \\
\text { error [\%] } \\
\text { (Alb 0.16) }\end{array}$ & $\begin{array}{r}\mathrm{CO}_{2} \text { column } \\
\text { error [\%] } \\
\text { (Alb 0.14) }\end{array}$ & $\begin{array}{r}\mathrm{O}_{2} \text { column } \\
\text { error [\%] } \\
(\mathrm{Alb} 0.20)\end{array}$ & $\begin{array}{r}\mathrm{XCO}_{2} \\
\text { error [\%] }\end{array}$ & $\begin{array}{r}\mathrm{XCH}_{4}\left(\mathrm{O}_{2}\right) \\
\text { error [\%] }\end{array}$ \\
\hline $\begin{array}{l}\text { OPAC urban } \\
\text { OPAC background }\end{array}$ & -0.73 & -0.82 & -0.43 & -0.39 & -0.30 \\
\hline $\begin{array}{l}\text { overestimation } \\
\text { (urban-background) }\end{array}$ & -0.88 & -0.97 & -0.47 & -0.50 & -0.41 \\
\hline
\end{tabular}

$1 \mathrm{ppm}$ ) is however close to the detection limit of our SCIAMACHY retrievals even if three years of data are averaged. As has been shown, the single measurement precision is about $1-2 \%$ corresponding to about $4-7$ ppm. In order to detect a signal on the order of $1 \mathrm{ppm}$ the (single measurement) precision has to be improved by at least factor of 7. Assuming that the precision improves with the square root of the number of measurements added this means that more than
50 measurements need to be averaged per $0.5^{\circ} \times 0.5^{\circ}$ gridcell before a 1 ppm signal can be detected at this resolution. For the three years average this is achieved for nearly the entire region shown in Fig. 17 (except for coastal areas including parts of the Netherlands) but not for one year averages. For the south-western part of the Netherlands, for example, there are nearly no data during 2004 and the elevated $\mathrm{CO}_{2}$ over the Netherlands is mainly due to 2003 data (slight elevation) and 
2005 data (significant elevation). As a consequence we found that the elevated $\mathrm{CO}_{2}$ over the Netherlands is less stable (e.g. with respect to smaller averaging time periods) compared to the German part of the Rhine-Main area where significantly more data are available and where we observe regionally elevated $\mathrm{CO}_{2}$ also in yearly averages.

\section{Conclusions}

We have presented and discussed a multi-year global data set of atmospheric carbon dioxide column-averaged dry air mole fractions, $\mathrm{XCO}_{2}$. The $\mathrm{XCO}_{2}$ data set has been retrieved from the spectral near-infrared nadir observations of the SCIAMACHY instrument onboard the European environmental satellite ENVISAT using the significantly improved version 1.0 of the retrieval algorithm WFM-DOAS. The quality of the global SCIAMACHY $\mathrm{XCO}_{2}$ data set has been assessed by a combination of an error analysis using simulated retrievals, comparisons with a limited number of independent $\mathrm{XCO}_{2}$ measurements obtained using ground-based FTS, and comparisons with $\mathrm{XCO}_{2}$ from NOAA's global assimilation system CarbonTracker.

The largest differences with respect to the reference data which we have identified were over the Sahara where SCIAMACHY $\mathrm{XCO}_{2}$ is overestimated by a several percent under conditions of highly elevated desert dust storm aerosol as identified using TOMS/Earth Probe Absorbing Aerosol Index (AAI) (Herman et al., 1997). We have shown that $\mathrm{XCO}_{2}$ has smaller errors in this case than the absolute $\mathrm{CO}_{2}$ columns due to cancellation of errors when dividing the retrieved $\mathrm{CO}_{2}$ columns by simultaneously retrieved $\mathrm{O}_{2}$. We found however that this does not fully eliminate all aerosol related errors. Therefore, for most of the results presented here, we have applied a threshold filter based on the AAI to remove strongly aerosol contaminated scenes.

Currently, the $\mathrm{CO}_{2}$ column-averaged dry air mole fraction is only measured at a few ground stations and only recently by a new network of FTS stations (see, for example, the Total Carbon Column Observing Nework (TCCON) website: http://www.tccon.caltech.edu). The comparison of the SCIAMACHY $\mathrm{XCO}_{2}$ with the $\mathrm{XCO}_{2}$ FTS measurements at Park Falls, Wisconsin, USA and Bremen, Germany, which are both part of TCCON, showed good agreement with respect to the amplitude and the phase of the $\mathrm{CO}_{2}$ seasonal cycle for the monthly composite averages.

To assess the quality of the data globally, we have performed comparisons with the recently released output of NOAA's global assimilation system CarbonTracker. To enable a meaningful comparison, the CarbonTracker data have been sampled in space and time as SCIAMACHY measures and the SCIAMACHY averaging kernels have been applied to CarbonTracker to take the altitude sensitivity of the SCIAMACHY $\mathrm{CO}_{2}$ retrievals into account. In general we found reasonable to good agreement with CarbonTracker, for ex- ample concerning the increase of carbon dioxide with time globally and concerning the $\mathrm{CO}_{2}$ seasonal cycle over the Northern Hemisphere where a large uptake of atmospheric $\mathrm{CO}_{2}$ is observed typically in July and August. This uptake is attributed primarily to vegetation during the growing season, i.e., by the terrestrial biosphere. On the regional scale the satellite data show in general similar spatial pattern as CarbonTracker but exhibit typically higher variability.

From the comparison with the limited reference data we conclude that the SCIAMACHY $\mathrm{XCO}_{2}$ data set over land can be characterized by a systematic low bias of about $1.5 \%$ as concluded from the mean difference relative to the FTS and CarbonTracker, and by a relative accuracy of about $1-2 \%$ for monthly averages at a horizontal resolution of $7^{\circ} \times 7^{\circ}$ as concluded from the comparison of regional $\mathrm{XCO}_{2}$ anomalies with CarbonTracker. We further estimate the single ground pixel retrieval precision to be about $1-2 \%(\sim 6 \mathrm{ppm})$ as concluded, for example, from the mean of the standard deviations of the daily SCIAMACHY $\mathrm{XCO}_{2}$ at given locations.

When averaging the SCIAMACHY $\mathrm{XCO}_{2}$ over all three years we find elevated $\mathrm{CO}_{2}$ over the highly populated area of western central Germany and parts of the Netherlands ("Rhine-Main area") and other regions (US East Coast, parts of Japan, e.g., around Tokyo), reasonably well correlated with EDGAR anthropogenic $\mathrm{CO}_{2}$ emissions, indicating that regionally elevated $\mathrm{CO}_{2}$ arising from regional anthropogenic $\mathrm{CO}_{2}$ emissions can potentially be detected from space.

In summary, we have shown that significant progress has been made in our understanding and the quality of the carbon dioxide data product derived from the SCIAMACHY nadir observations and that the new WFM-DOAS data set comes closer to the demanding accuracy and precision requirements of $1 \%$ or better needed for significant $\mathrm{CO}_{2}$ surface flux uncertainty reduction. We identified primarily two aspects which need further study: (i) the identification of the cause (or causes) of the significantly (about a factor of two) higher variability of the SCIAMACHY $\mathrm{XCO}_{2}$ compared to CarbonTracker, and (related to this) (ii) an assessment of the significance of the observed regional $\mathrm{XCO}_{2}$ spatio-temporal pattern with respect to their information content on regional $\mathrm{CO}_{2}$ sources and sinks.

The SCIAMACHY $\mathrm{XCO}_{2}$ data set presented and discussed here is available from the authors on request. Details concerning data format and access as well as supplementary information such as monthly composite maps covering the entire three years time period are given on the SCIAMACHY/WFM-DOAS website http://www.iup.uni-bremen.de/sciamachy/NIR_NADIR _ WFM_DOAS/index.html.

In the future we will aim at further improving the retrieval algorithm taking into account, for example, updates of the spectroscopic line parameters. We will also aim at further reducing light path related errors (caused by the variability of aerosols and undetected clouds, in particular subvisual cirrus clouds) as well as errors caused by the variability 
of meteorological parameters, e.g., by taking advantage of temperature and pressure vertical profiles from meteorological analysis. One of the challenges will be to significantly further improve the accuracy without increasing the required processing time by many orders of magnitude.

Acknowledgements. We thank ESA and DLR for providing us with the SCIAMACHY Level 1 data. We also thank R. Washenfelder, G. Aleks, G. Toon, and P. Wennberg at Caltech and NASA JPL for making available the Park Falls FTS data. The FTS measurements at Park Falls were obtained with support from NASA. We further thank the NASA/GSFC TOMS Ozone Processing Team (OPT) for providing TOMS/EP AAI data and NOAA/ESRL/GMD (P. Tans, W. Peters, and colleagues) for the CarbonTracker $\mathrm{CO}_{2}$ fields. The MODIS/Terra AOD retrievals (Level 3, collection 5) have been obtained from http://modis-atmos.gsfc.nasa.gov/. The preliminary subvisual cirrus cloud retrievals have been obtained from E. Martins, LMD/IPSL, Palaiseau, France. The gridded population density data were obtained from the Center for International Earth Science Information Network (CIESIN), Columbia University and Centro Internacional de Agricultura Tropical, available at http:://sedac.ciesin.columbia.edu/gwp. The anthropogenic $\mathrm{CO}_{2}$ emissions have been obtained from the Emission Database for Global Atmospheric Research (EDGAR) (http://www.mnp.nl/edgar/). This paper has been significantly improved due to comments on earlier versions of the manuscript from: P. Tans (NOAA), W. Peters (NOAA), P. Bergamaschi (EC-JRC, Ispra, Italy), P. Wennberg (Caltech), G. Toon (JPL), R. Washenfelder (NOAA), M. Heimann (MPI Biogeochemistry, Jena, Germany), and A. Goede (formerly KNMI, now FOM Institute for Plasma Physics, Nieuwegein, The Netherlands). We also thank two anonymous referees and S. Houweling, SRON, The Netherlands, for helpful comments. Funding for this study came from DLR-Bonn (grant 50EE0027 (SADOS), 50EE0727 (SADOS-2) and 50EE0507 (SCIACO2)), ESA (GMES Service Element (GSE) project PROMOTE led by DLR-Oberpfaffenhofen) and from the University and the State of Bremen. We acknowledge exchange of information within the European Commission Network of Excellence ACCENT.

\section{Edited by: T. Garrett}

\section{References}

Aben, I., Hasekamp, O., and Hartmann, W.: Uncertainties in the space-based measurements of $\mathrm{CO}_{2}$ columns due to scattering in the Earth's atmosphere, J. Quant. Spectrosc. Rad. Transfer, 104, 450-459, 2006.

Aumann, H. H., Gregorich, D., and Gaiser, S.: AIRS hyperspectral measurements for climate research: Carbon dioxide and nitrous oxide effects, Geophys. Res. Lett., 32, L05806, doi:10.1029/2004GL021784, 2005.

Barkley, M. P., Frieß, U., and Monks, P. S.: Measuring atmospheric $\mathrm{CO}_{2}$ from space using Full Spectral Initiation (FSI) WFM-DOAS, Atmos. Chem. Phys., 6, 3517-3534, 2006a, http://www.atmos-chem-phys.net/6/3517/2006/.

Barkley, M. P., Monks, P. S., Frieß, U., Mittermeier, R. L., Fast, H., Körner, S., and Heimann, M.: Comparisons between SCIAMACHY atmospheric $\mathrm{CO}_{2}$ retrieved using (FSI) WFM-DOAS to ground based FTIR data and the TM3 chemistry transport model, Atmos. Chem. Phys., 6, 4483-4498, 2006b, http://www.atmos-chem-phys.net/6/4483/2006/.

Barkley, M. P., Monks, P. S., and Engelen, R. J.: Comparison of SCIAMACHY and AIRS $\mathrm{CO}_{2}$ measurements over North America during the summer and autumn of 2003, Geophys. Res. Lett., 33, L20805, doi:10.1029/2006GL026807, 2006, 2006 c.

Barkley, M. P., Monks, P. S., Hewitt, A. J., Machida, T., Desai, A., Vinnichenko, N., Nakazawa, T., Yu Arshinov, M., Fedoseev, N., and Watai, T.: Assessing the near surface sensitivity of SCIAMACHY atmospheric $\mathrm{CO}_{2}$ retrieved using (FSI) WFM-DOAS, Atmos. Chem. Phys., 7, 3597-3619, 2007, http://www.atmos-chem-phys.net/7/3597/2007/.

Berk, A., Bernstein, L. S., Anderson, G. P., Acharya, P. K., Robertson, D. C., Chetwynd, J. H., Adler-Golden, S. M.: MODTRAN cloud and multiple scattering upgrades with application to AVIRIS, Remote Sens. Environ., 65(3), 367-375, 1998.

Bösch, H., Toon, G. C., Sen, B., Washenfelder, R. A., Wennberg, P. O., Buchwitz, M., de Beek, R., Burrows, J. P., Crisp, D., Christi, M., Connor, B. J., Natraj, V., and Yung, Y. L.: Space-based nearinfrared $\mathrm{CO}_{2}$ measurements: Testing the Orbiting Carbon Observatory retrieval algorithm and validation concept using SCIAMACHY observations over Park Falls, Wisconsin, J. Geophys. Res., 111, D23302, doi:10.1029/2006JD007080, 2006.

Bousquet, P., Ciais, P., Peylin, P., Ramonet, M., and Monfray, P.: Inverse modeling of annual atmospheric $\mathrm{CO}_{2}$ sources and sinks 1. Method and control inversion, J. Geophys. Res., 104(D21), 26 161-26 178, 1999.

Bovensmann, H., Burrows, J. P., Buchwitz, M., Frerick, J., Noël, S., Rozanov, V. V., Chance, K. V., and Goede, A.: SCIAMACHY Mission Objectives and Measurement Modes, J. Atmos. Sci., 56, 127-150, 1999.

Bril, A., Oshchepkov, S., Yokota, T., and Inoue, G.: Parameterization of aerosol and cirrus cloud effects on reflected sunlight spectra measured from space: application of the equivalence theorem, Appl. Optics, 46(13), 2460-2470, 2007.

Buchwitz, M., Schneising, O., Burrows, J. P., Bovensmann, H., Reuter, M., and Notholt, J.: First direct observation of the atmospheric $\mathrm{CO}_{2}$ year-to-year increase from space, Atmos. Chem. Phys., 7, 4249-4256, 2007, http://www.atmos-chem-phys.net/7/4249/2007/.

Buchwitz, M., de Beek, R., Noël, S., Burrows, J. P., Bovensmann, H., Schneising, O., Khlystova, I., Bruns, M., Bremer, H., Bergamaschi, P., Körner, S., and Heimann, M.: Atmospheric carbon gases retrieved from SCIAMACHY by WFM-DOAS: version $0.5 \mathrm{CO}$ and $\mathrm{CH}_{4}$ and impact of calibration improvements on $\mathrm{CO}_{2}$ retrieval, Atmos. Chem. Phys., 6, 2727-2751, 2006a,

http://www.atmos-chem-phys.net/6/2727/2006/.

Buchwitz, M., de Beek, R., Burrows, J. P., Bovensmann, H., Warneke, T., Notholt, J., Meirink, J. F., Goede, A. P. H., Bergamaschi, P., Körner, S., Heimann, M., and Schulz, A.: Atmospheric methane and carbon dioxide from SCIAMACHY satellite data: Initial comparison with chemistry and transport models, Atmos. Chem. Phys., 5, 941-962, 2005a, http://www.atmos-chem-phys.net/5/941/2005/.

Buchwitz, M., de Beek, R., Noël, S., Burrows, J. P., Bovensmann, H., Bremer, H., Bergamaschi, P., Körner, S., and Heimann, M.: Carbon monoxide, methane, and carbon dioxide retrieved from SCIAMACHY by WFM-DOAS: year 2003 initial data set, At- 
mos. Chem. Phys., 5, 3313-3329, 2005b,

http://www.atmos-chem-phys.net/5/3313/2005/.

Buchwitz, M. and Burrows, J. P.: Retrieval of $\mathrm{CH}_{4}, \mathrm{CO}$, and $\mathrm{CO}_{2}$ total column amounts from SCIAMACHY near-infrared nadir spectra: Retrieval algorithm and first results, in: Remote Sensing of Clouds and the Atmosphere VIII, edited by: Schäfer, K. P., Comèron, A., Carleer, M. R., and Picard, R. H. (PDF file available from WFM-DOAS web site http://www.iup.uni-bremen.de/ sciamachy/NIR_NADIR_WFM_DOAS/index.html), Proceedings of SPIE, 5235, 375-388, 2004.

Buchwitz, M., Rozanov, V. V., and Burrows, J. P.: A correlated-k distribution scheme for overlapping gases suitable for retrieval of atmospheric constituents from moderate resolution radiance measurements in the visible/near-infrared spectral region, J. Geophys. Res., 105, 15 247-15 262, 2000 b.

Buchwitz, M., Strahlungstransport und Inversions-Algorithmen zur Ableitung atmosphärischer Spurengasinformationen aus Erdfernerkundungsmessungen in Nadirgeometrie im ultravioletten bis nahinfraroten Spektralbereich am Beispiel SCIAMACHY, $\mathrm{PhD}$ thesis University of Bremen (in German), (PDF file available from University of Bremen electronic library http: //nbn-resolving.de/urn:nbn:de:gbv:46-diss000000338 ), p. 318, 2000a.

Burrows, J. P., Schneider, W., Geary, J. C., Chance, K. V., Goede, A. P. H., Aarts, H. J. M., de Vries, J., Smorenburg, C., and Visser, H.: Atmospheric remote sensing with SCIAMACHY, Digest of Topical Meeting on Optical Remote Sensing of the Atmosphere, Optical Society of America, Washington D.C., 4, 71-74, 1990.

Burrows, J. P. and Chance, K. V., Scanning imaging absorption spectrometer for atmospheric chartography, Future European and Japanese Remote Sensing Sensors and Programs, edited by: Slater, P. N., Proc. SPIE, 1490, 146-155, 1991.

Burrows, J. P., Hölzle, E., Goede, A. P. H., Visser H., and Fricke, W.: SCIAMACHY - Scanning Imaging Absorption Spectrometer for Atmospheric Chartography, Acta Astronautica, 35(7), 445-451, 1995.

Chédin, A., Hollingsworth, A., Scott, N. A., Serrar, S., Crevoisier, C., and Armante, R., Annual and seasonal variations of atmospheric $\mathrm{CO}_{2}, \mathrm{~N}_{2} \mathrm{O}$ and $\mathrm{CO}$ concentrations retrieved from NOAA/TOVS satellite observations, Geophys. Res. Lett., 29(8), 1269, doi:10.1029/2001GL014082, 2002.

Chédin, A., Serrar, S, Scott, N. A., Crevoisier, C., and Armante, R., First global measurement of midtropospheric $\mathrm{CO} 2$ from NOAA polar satellites: Tropical zone, J. Geophys. Res., 108(D18), 4581, doi:10.1029/2003JD003439, 2003.

CIESIN/CIAT, CIESIN (Center for International Earth Science Information Network), Columbia University/CIAT (Centro Internacional de Agricultura Tropical): Gridded Population of the World Version 3 (GPWv3): Population Density Grids, Palisades, NY, Socioeconomic Data and Applications Center (SEDAC), Columbia University, available at: http://sedac.ciesin.columbia. edu/gpw, 2005.

Crisp, D., Atlas, R. M., Bréon, F.-M., Brown, L. R., Burrows, J. P., Ciais, P., Connor, B. J., Doney, S. C., Fung, I. Y., Jacob, D. J., Miller, C. E., O’Brien, D., Pawson, S., Randerson, J. T., Rayner, P., Salawitch, R. S., Sander, S. P., Sen, B., Stephens, G. L., Tans, P. P., Toon, G. C., Wennberg, P. O., Wofsy, S. C., Yung, Y. L., Kuang, Z., Chudasama, B., Sprague, G., Weiss, P., Pollock, R., Kenyon, D., and Schroll, S.: The Orbiting Carbon Observatory
(OCO) mission, Adv. Space Res., 34, 700-709, 2004.

Christi, M. J. and Stephens, G. L.: Retrieving profiles of atmospheric $\mathrm{CO}_{2}$ in clear sky and in the presence of thin cloud using spectroscopy from the near and thermal infrared: a preliminary case study, J. Geophys. Res., 109, D04316, doi:10.1029/2003JD004058, 2004.

Chevallier, F., Bréon, F.-M., and Rayner, P. J.: Contribution of the Orbiting Carbon Observatory to the estimation of $\mathrm{CO}_{2}$ sources and sinks: Theoretical study in a variational data assimilation framework, J. Geophys. Res., 112, D09307, doi:10.1029/2006JD007375, 2007.

Derwent, R. G., Ryall, D. B., Manning, A. J., Simmonds, P. G., ODoherty, S., Biraud, S., Ciais, P., Ramonet, M., and Jennings, S. G.: Continuous observations of carbon dioxide at Mace Head, Ireland from 1995 to 1999 and its net European ecosystem exchange, Atmos. Environ., 36, 2799-2807, 2002.

Dils, B., De Mazière, M., Müller, J. F., Blumenstock, T., Buchwitz, M., de Beek, R., Demoulin, P., Duchatelet, P., Fast, H., Frankenberg, C., Gloudemans, A., Griffith, D., Jones, N., Kerzenmacher, T., Mahieu, E., Mellqvist, J., Mikuteit, S., Mittermeier, R. L., Notholt, J., Schrijver, H., Smale, D., Strandberg, A., Stremme, W., Strong, K., Sussmann, R., Taylor, J., van den Broek, M., Warneke, T., Wiacek, A., and Wood, S.: Comparison between SCIAMACHY and ground-based FTIR data for total columns of $\mathrm{CO}, \mathrm{CH}_{4}, \mathrm{CO}_{2}$ and $\mathrm{N}_{2} \mathrm{O}$, Atmos. Chem. Phys., 6, 1953-1976, 2006a,

http://www.atmos-chem-phys.net/6/1953/2006/.

Dufour, E. and Bréon, F.-M.: Spaceborn estimate of atmospheric $\mathrm{CO}_{2}$ column by use of the differential absorption method: error analysis, Appl. Optics, 42, 3595-3609, 2003.

Engelen, R. J., Andersson, E., Chevallier, F., Hollingsworth, A., Matricardi, M., McNally, A. P., Thépaut, J.-N., and Watts, P. D., Estimating atmospheric $\mathrm{CO}_{2}$ from advanced infrared satellite radiances within an operational 4D-Var data assimilation system: Methodology and first results, J. Geophys. Res., 109, D19309, doi:10.1029/2004JD004777, 2004.

Engelen, R. J., and McNally, A. P., Estimating atmospheric $\mathrm{CO}_{2}$ from advanced infrared satellite radiances within an operational 4D-Var data assimilation system: Results and validation, J. Geophys. Res., 109, D18305, doi:10.1029/2005JD005982, 2005.

Frankenberg, C., Platt, U., and Wagner, T.: Iterative maximum a posteriori (IMAP-)DOAS for retrieval of strongly absorbing trace gases: Model studies for $\mathrm{CH}_{4}$ and $\mathrm{CO}_{2}$ retrieval from nearinfrared spectra of SCIAMACHY onboard ENVISAT, Atmos. Chem. Phys., 5, 9-22, 2005, http://www.atmos-chem-phys.net/5/9/2005/.

Gloudemans, A. M. S., Schrijver, H., Kleipool, Q., van den Broek, M. M. P., Straume, A. G., Lichtenberg, G., van Hess, R. M., Aben, I., and Meirink, J. F.: The impact of SCIAMACHY nearinfrared instrument calibration on $\mathrm{CH}_{4}$ and $\mathrm{CO}$ total columns, Atmos. Chem. Phys., 5, 2369-2383, 2005, http://www.atmos-chem-phys.net/5/2369/2005/.

Goody, R. M. and Yung, Y. L.: Atmospheric Radiation, Oxford University Press, New York, 1989.

Gurney, K. R., Law, R. M., Denning, A. S., Rayner, P. J., Baker, D., Bousquet, P., Bruhwiler, L., Chen, Y.-H., Ciais, P., Fan, S., Fung, I. Y., Gloor, M., Heimann, M., Higuchi, K., John, J., Maki, T., Maksyutov, S., Masarie, K., Peylin, P., Prather, M., Pak, B. C., Randerson, J., Sarmiento, J., Taguchi, S., Takahashi, T., and 
Yuen, C.-W.: Towards robust regional estimates of $\mathrm{CO}_{2}$ sources and sinks using atmospheric transport models, Nature, 415, 626630, 2002.

Hamazaki, T., Kaneko, Y., and Kuze, A.: Carbon dioxide monitoring from the GOSAT satellite, Proceedings XXth ISPRS conference, Istanbul, Turkey, 12-23 July 2004, p. 3 (http://www.isprs. org/istanbul2004/comm7/papers/43.pdf), 2004.

Herman, J. R., Bhartia, P. K., Torres, O., Hsu, C., Seftor, C., and Celarier, E.: Global distribution of UV absorbing aerosols from Nimbus7/TOMS data, J. Geophys. Res., 102, 16911-16922, 1997.

Houweling, S., Bréon, F.-M., Aben, I., Rödenbeck, C., Gloor, M., Heimann, M., and Ciais, P.: Inverse modeling of $\mathrm{CO}_{2}$ sources and sinks using satellite data: A synthetic inter-comparison of measurement techniques and their performance as a function of space and time, Atmos. Chem. Phys., 4, 523-538, 2004, http://www.atmos-chem-phys.net/4/523/2004/.

Houweling, S., Hartmann, W., Aben, I., Schrijver, H., Skidmore, J., Roelofs, G.-J., and Bréon, F.-M.: Evidence of systematic errors in SCIAMACHY-observed $\mathrm{CO}_{2}$ due to aerosols, Atmos. Chem. Phys., 5, 3003-3013, 2005,

http://www.atmos-chem-phys.net/5/3003/2005/.

Houweling, S.: Interactive comment on Three years of greenhouse gas column-averaged dry air mole fractions retrieved from satellite - Part 1: Carbon dioxide, Atmos. Chem. Phys. Discuss., 8, S2530-S2534, 2008.

IPCC: Contribution of working group I to the Third Assessment Report (TAR) of the Intergovernmental Panel on Climate Change (IPCC), edited by: Houghton, J. T., Ding, Y., Griggs, D., Noguer, M., van der Linden, P. J., and Xiaosu, D., Cambridge University Press, Cambridge (UK), New York (USA), 881 pp., 2001.

IPCC, Solomon, S., Qin, D., Manning, M., Chen, Z., Marquis, M., Averyt, K. B., Tignor, M., and Miller, H. L.: Climate change 2007: The physical science basis, Contribution of working group I to the Fourth Assessment Report of the Intergovernmental Panel on Climate Change (IPCC), Cambridge University Press, Cambridge (UK), New York (USA), 996 pp., 2007.

Krol, M. C., Houweling, S., Bregman, B., van den Broek, M., Segers, A., van Velthoven, P., Peters, W., Dentener, F., and Bergamaschi, P.: The two-way nested global chemistry-transport zoom model TM5: Algorithm and applications, Atmos. Chem. Phys., 5, 417-432, 2005,

http://www.atmos-chem-phys.net/5/417/2005/.

Kuang, Z., Margolis, J., Toon, G., Crisp, D., and Yung, Y.: Spaceborne measurements of atmospheric $\mathrm{CO}_{2}$ by high-resolution NIR spectrometry of reflected sunlight: an introductory study, Geophys. Res. Lett., 29, 1716, doi:10.1029/2001GL014298, 2002.

Liu, C.: Geographical and seasonal distribution of tropical tropopause thin clouds and their relation to deep convection and water vapor viewed from satellite measurements, J. Geophys. Res., 112, D09205, doi:10.1029/2006JD007479, 2007.

Mao, J. and Kawa, S. R.: Sensitivity studies for space-based measurement of atmospheric total column carbon dioxide by reflected sunlight, Appl. Optics, 43, 914-927, 2004.

Miller, C. E., Crisp, D., DeCola, P. L., et al.: Precision requirements for space-based $\mathrm{X}_{\mathrm{CO}_{2}}$ data, J. Geophys. Res., 112, D10314, doi:10.1029/2006JD007659, 2007.

Natraj, V., Spurr, R. J. D., Bösch, H., Jiang, Y., and Yung, Y. L.: Evaluation of errors from neglecting polarization in the forward modeling of $\mathrm{O}_{2}$ A band measurements from space, with relevance to $\mathrm{CO}_{2}$ column retrieval from polarization-sensitive instruments, J. Quant. Spectrosc. Rad. Trans., 103, 245-259, 2007.

O'Brien, D. M. and Rayner, P. J.: Global observations of the carbon budget 2. $\mathrm{CO}_{2}$ column from differential absorption of reflected sunlight in the $1.61 \mu \mathrm{m}$ band of $\mathrm{CO}_{2}$, J. Geophys. Res., 107, 4354, doi:10.1029/2001JD000617, 2002.

Olivier, J.G.J., Van Aardenne, J.A., Dentener, F., Ganzeveld, L., and Peters, J. A. H. W.: Recent trends in global greenhouse gas emissions: regional trends and spatial distribution of key sources, in: Non- $\mathrm{CO}_{2}$ Greenhouse Gases (NCGG-4), A. van Amstel (Coord.), Millpress, Rotterdam, ISBN 90-5966-043-9, 325-330, 2005.

Olsen, S. C. and Randerson, J. T.: Differences between surface and column atmospheric $\mathrm{CO}_{2}$ and implications for carbon cycle research, J. Geophys. Res., 109, D02301, doi:10.1029/2003JD003968, 2004.

Palmer, P. I., Barkley, M. P., and Monks, P. S.: Interpreting the variability of $\mathrm{CO}_{2}$ columns over North America using a chemistry transport model: application to SCIAMACHY data, Atmos. Chem. Phys. Discuss., 8, 7339-7371, 2008,

http://www.atmos-chem-phys-discuss.net/8/7339/2008/.

Patra, P. K., Gurney, K. R., Denning, A. S., Maksyutov, S., Nakazawa, T., Baker, D. Bousquet, P., Bruhwiler, L., Chen, Y.H., Ciais, P., Fan, S., Fung, I., Gloor, M., Heimann, M., Higuchi, K., John, L., Law, R. M., Maki, T., Pak, B. C., Peylin, P., Prather, M., Rayner, P. J., Sarmiento, J., Taguchi, S., Takahashi, T., and Yuen, C.-W.: Sensitivity of inverse estimation of annual mean $\mathrm{CO}_{2}$ sources and sinks to ocean-only sites versus allsites observational networks, Geophys. Res. Lett., 33, L05814, doi:10.1029/2005GL025403, 2006.

Peters, W., Jacobson, A. R., Sweeney, C., Andrews, A. E., Conway, T. J., Masarie, K., Miller, J. B., Bruhwiler, L. M. P., Pétron, G., Hirsch, A. I., Worthy, D. E. J., van der Werf, G. R., Randerson, J. T., Wennberg, P. O., Krol, M. C., and Tans, P. P.: An atmospheric perspective on North American carbon dioxide exchange: CarbonTracker, Proceedings of the National Academy of Sciences (PNAS) of the United States of America, 27 November 2007, 104(48), 18 925-18 930, 2007.

Peylin, P., Rayner, P. J., Bousquet, P., Carouge, C., Hourdin, F., Heinrich, P., Ciais, P., and AEROCARB contributors: Daily $\mathrm{CO}_{2}$ flux estimates over Europe from continuous atmospheric measurements; 1, inverse methodology, Atmos. Chem. Phys., 5, 3173-3186, 2005, http://www.atmos-chem-phys.net/5/3173/2005/.

Press, W., Teukolsky, S., Vetterling, W., and Flannery, B.: Numerical Recipes in Fortran, Cambridge University Press, London, 1992.

Rayner, P. J. and O'Brien, D. M.: The utility of remotely sensed $\mathrm{CO}_{2}$ concentration data in surface inversions, Geophys. Res. Lett., 28, 175-178, 2001.

Rödenbeck, C., Houweling, S., Gloor, M., and Heimann, M.: $\mathrm{CO}_{2}$ flux history 1982-2001 inferred from atmospheric data using a global inversion of atmospheric transport, Atmos. Chem. Phys., 3, 1919-1964, 2003, http://www.atmos-chem-phys.net/3/1919/2003/.

Rothman, L. S., Barbe, A., Benner, D. C., Brown, L. R., CamyPeyret, C., Carleer, M. R., Chance, K., Clerbaux, C., Dana, V., Devi, V. M., Fayt, A., Flaud, J. M., Gamache, R. R., Goldman, 
A., Jacquemart, D., Jucks, K. W., Lafferty, W. J., Mandin, J. Y., Massie, S. T., Nemtchinov, V., Newnham, D. A., Perrin, A., Rinsland, C. P., Schroeder, J., Smith, K. M., Smith, M. A. H., Tang, K., Toth, R. A., Vander Auwera, J., Varanasi, P., and Yoshino, K.: The HITRAN molecular spectroscopic database: edition of 2000 including updates through 2001, J. Quant. Spectrosc. Radiat. Transfer, 82, 5-44, 2003.

Rothman, L. S., Jaquemart, D., Barbe, A., Benner, D. C., Birk, M., Brown, L. R., Carleer, M. R., Chackerian, C., Chance, K., Coudert, L. H., Dana, V., Devi, V. M., Flaud, J.-M., Gamache, R. R., Goldman, A., Hartmann, J.-M., Jucks, K. W., Maki, A. G., Mandin, J.-Y., Massie, S. T., Orphal, J., Perrin, A., Rinsland, C. P., Smith, M. A. H., Tennyson, J., Tolchenov, R. N., Toth, R. A., Vander Auwera, J., Varanasi, P., and Wagner, G.: The HITRAN 2004 molecular spectroscopic database, J. Quant. Spectrosc. Radiat. Transfer, 96, 139-204, 2005.

Schneising, O., Buchwitz, M., Burrows, J. P., Bovensmann, H., Bergamaschi, P., and Peters, W.: Three years of column-averaged dry air mole fractions of greenhouse gases retrieved from satellite - Part 2: Methane, Atmos. Chem. Phys. Discuss., 8, 8273-8326, 2008 , http://www.atmos-chem-phys-discuss.net/8/8273/2008/.

Stephens, B. B., Gurney, K. R., Tans, P. P., Sweeney, C., Peters, W., Bruhwiler, L., Ciais, P., Ramonet, M., Bousquet, P., Nakazawa, T., Aoki, S., Machida, T., Inoue, G., Vinnichenko, N., Lloyd, J., Jordan, A., Heimann, M., Shibistova, O., Langenfelds, R. L., Steele, L. P., Francey, R. J., and Denning, A. S.: Weak northern and strong tropical land carbon uptake from vertical profiles of atmospheric $\mathrm{CO}_{2}$, Science, 316, 1732-1735, 2007.
Strow, L. L., Hannon, S. E., De-Souza Machado, S., Motteler, H. E., and Tobin, D. C.: Validation of the Atmospheric Infrared Sounder radiative transfer algorithm, J. Geophys. Res., 111, D09S06, doi:10.1029/2005JD006146, 2006.

Tolton, B. T. and Plouffe, D., Sensitivity of radiometric measurements of the atmospheric $\mathrm{CO}_{2}$ column from space, Appl. Optics, 40, 1305-1313, 2001.

van Diedenhoven, B., Hasekamp, O. P., and Aben, I.: Surface pressure retrieval from SCIAMACHY measurements in the $\mathrm{O}_{2} \mathrm{~A}$ band: validation of the measurements and sensitivity on aerosols, Atmos. Chem. Phys., 5, 2109-2120, 2005, http://www.atmos-chem-phys.net/5/2109/2005/.

Warneke, T., de Beek, R., Buchwitz, M., Notholt, J., Schulz, A., Velazco, V., and Schrems, O.: Shipborne solar absorption measurements of $\mathrm{CO}_{2}, \mathrm{CH}_{4}, \mathrm{~N}_{2} \mathrm{O}$, and $\mathrm{CO}$ and comparison with SCIAMACHY WFM-DOAS retrievals, Atmos. Chem. Phys., 5, 2029-2034, 2005, http://www.atmos-chem-phys.net/5/2029/2005/.

Washenfelder, R. A., Toon, G. C., Blavier, J.-F., Yang, Z., Allen, N. T., Wennberg, P. O., Vay, S. A., Matross, D. M., and Daube, B. C.: Carbon dioxide column abundances at the Wisconsin Tall Tower site, J. Geophys. Res., 111, D22305, doi:10.1029/2006JD007154, 2006. 